\title{
Study on Mechanical Behavior and Seepage Characteristics of Coal Mass during Unloading
}

\author{
Yan Wang, 1 Yongsheng Han $\mathbb{D}^{2}$ and Fei Liu $\mathbb{D}^{3}$ \\ ${ }^{1}$ Rizhao Polytechnic, Rizhao, Shandong 276800, China \\ ${ }^{2}$ Department of Water Resources Engineering, Shandong Water Conservancy Vocational College, Rizhao, Shandong 276826, China \\ ${ }^{3}$ School of Resources and Civil Engineering, Suzhou University, Suzhou, Anhui 234000, China
}

Correspondence should be addressed to Fei Liu; szxylf@126.com

Received 23 June 2021; Revised 31 August 2021; Accepted 8 October 2021; Published 31 October 2021

Academic Editor: Feng Du

Copyright (c) 2021 Yan Wang et al. This is an open access article distributed under the Creative Commons Attribution License, which permits unrestricted use, distribution, and reproduction in any medium, provided the original work is properly cited.

With the increase of buried depth, the content of gas increases gradually. The gas in the mining process will lead to gas gush and other dynamic disasters, or even coal and gas gushing in front of the working face. Therefore, the study on the permeability distribution of coal and the surrounding rock is the core work of coal and gas mining at the same time. To study the mechanical behaviors and seepage characteristics of coal mass during unloading is to prepare for coal and gas mining in the future, which can not only ensure the safety of operators to the maximum extent but also increase the mining rate as much as possible. Based on the stress-strain curve and seepage curve, the brittleness index and seepage characteristics of coal are analyzed. The greater the brittleness index is, the more likely the coal mass is to produce cracks, and then to form large cracks, or even fracture. Through the study of brittleness index and seepage characteristics of coal mass, the mechanical behavior of coal mass can be easily obtained, so as to guide the mining of coal mass.

\section{Introduction}

China has been advocating the conversion of polluting energy to clean energy, but as a big energy consumer, coal energy will always play a dominant role in the future for a long time $[1,2]$. The present situation in China is that there are a lot of coal resources but little oil resources. The proven coal reserves of China account for $12.6 \%$ of the world's coal reserves, and the recoverable amount ranks the third and the output ranks the first in the world [3-5]. As for the quality of coal, there are less high-quality coal and more inferior coal [6], and the surface coal reserves are limited after all, as well as the large demand for coal energy, the mining of coal must be advanced to a deeper level [7-9]. As a result, deeper mining will face more complex coal strata, and mining work will also face more complex surrounding rock stress state $[10$, $11]$, making mining work with more risks, such as gas explosion, coal and gas outburst, flooding, roof accident, poisoning, and asphyxiation [12, 13]. Therefore, while coal mining brings huge economic benefits to people, exploring how to prevent and reduce the occurrence of hazards in the process of coal mining can not only guarantee the safe and efficient operation of coal work but also provide a strong scientific support for mining work $[14,15]$.

The study on coal mass under real external force can reveal the influence of mining on coal mass, so it is very important to reduce the stress of coal mass from the perspective of experiment $[16,17]$. In view of this, we study the mechanical characteristics and seepage characteristics of coal mass affected by real external forces and to further explore the development law of coal mass fractures [18-20]. In view of the mechanical influence and seepage characteristics of coal mass under triaxial test, scholars have done a lot of research [21-23]. Bieniawaski [24] studied the size effect of coal and the stress-strain law under triaxial conditions. Wang et al. [25] conducted coal permeability tests under different confining pressure to monitor the deformation and permeability evolution of coal. Yin et al. [26] studied the mechanical properties and seepage characteristics of raw coal by using triaxial tests. It was found that different 
loading and unloading paths (different loading speed, unloading speed, and starting point of loading and unloading) have important influence on the mechanical and seepage characteristics of raw coal, and know that the failure mode of raw coal is tensile shear composite failure. In terms of numerical simulation, Xue et al. [27-29] established a permeability model for damaged excavated coal for simulation analysis. The research shows that the mechanical properties of coal will change significantly, and the permeability of coal will increase before and after the peak point, but the amount of increase is different. Liu [30] studied the deformation, failure, and seepage characteristics of coal containing gas and concluded that the strength and stiffness of raw coal decrease with the increase of gas, and the raw coal gradually transformed from the original brittle failure to the ductile shear failure. There are many pores in the interior of coal, and gas exists in free and adsorbed states. The damage and fracture of coal just release the adsorbed gas, which increases the mining benefit of gas. Yuan et al. [31] studied the thermal-fluid-solid coupling model of gas bearing coal seam, carried out the numerical simulation of heat injection promoting gas drainage, and verified the feasibility of injecting heat into coal seam to promote gas drainage. Zhao et al. [32] made a numerical analysis on the gas drainage performance of coal seams with different structural deformation coal seams and complete coal seams. Guo et al. [33] focused on the criterion of coal seam fracture caused by cumulative blasting and summarized the fracture zone and fracture propagation process of coal. Xue et al. [34-36] established the analytical model of coal seam gas fracturing damage characteristics by studying the media fracturing characteristics and its deformation characteristics and analyzed the law of gas diffusion and migration. Anyim et al. [37] studied the critical stress fault in geothermal area by using the thermal hydrological mechanical coupling model to explore the evolution law of its permeability. Sidiq et al. [38] studied the permeability of reservoir rocks under high temperature and high pressure. In terms of damage and fracture evolution in the process of coal seepage, Chen [39] studied the stress-strain-permeability variation characteristics of coal mass and concluded that soft coal has more pores, more gas adsorption, and higher gas content than hard coal. In addition, the permeability of coal mass shows a " $V$ " shape change. Xia et al. [40] used coupled rock triaxial test system to study the characteristics of seepage in the post-peak fracture stage of rock. The permeability of coal decreases instead of increasing, which indicates that the deformation of coal fractures has an irreversible process and the fracture opening becomes smaller. When unloading to a certain value, all levels of permeability become smaller, indicating that the recovery of permeability of coal has a lag.

Based on the above research findings, the stress-axial strain curve was obtained through triaxial tests, and the whole stage from loading to failure of coal mass was analyzed. The permeability of coal mass measured by the tests was combined with the graph to analyze the seepage characteristics of coal mass. And draw on scholars on the research of brittleness index, combined with the obtained data to check the brittleness index, to get the pattern of specific brittleness index.

\section{Study on Mechanical Behavior of Coal Mass}

2.1. The Acquisition and Preparation of Coal. The coal samples of this test are collected from a working face of mine. Because there are significant differences in the internal structure of coal and rock under geological action, the mechanical properties are discrete and heterogeneous. Therefore, the samples of this test are all taken from rock strata at the same location and at the same depth. In addition, try to ensure that the sampled rock blocks are complete and uniform, large in size, and sufficient for sampling, so as to reduce the error of the experiment. The processing of coal samples is carried out in accordance with the coal industry standard "Determination Method of Physical and Mechanical Properties of Coal." Cylinder with diameter of $50 \mathrm{~mm}$ is drilled through the diamond hollow drill of vertical core-taking machine, and then cylindrical samples of different lengths $(100 \mathrm{~mm})$ are cut by automatic rock cutting machine. Finally, the two end faces are ground flat on the doubleend grindstone machine. There are eight sets of samples, labeled A-1 through A-8, respectively.

In order to study the permeability characteristics of coal mass, eight groups of samples were treated separately. The samples A- 6 and A- 8 were humidified for $0 \mathrm{~h}$, and the moisture content was $2.4 \%$. The humidification treatment time of A-2 and A-4 samples is 17 hours, and the moisture content of the samples is $3.4 \%$. The humidification treatment time of A-3 and A-5 samples is 33 hours, and the moisture content is $4.4 \%$. The humidification treatment time of $\mathrm{A}-1$ and $\mathrm{A}-7$ samples is 69 hours, and the moisture content is $5.5 \%$. The eight groups of samples were divided into four groups with different water content. The confining pressure is $5 \mathrm{MPa}$.

2.2. Test Equipment. The loading system is microcomputer controlled electrohydraulic servo testing machine. During the loading process, the system can collect load, displacement, and other data at the same time. The data acquisition system uses stress sensor, displacement sensor, and static strain gauge to measure the load and longitudinal and transverse deformation of the coal sample. As shown in the figure, the strain acquisition instrument has 20 channels, and each measuring point is automatically balanced, respectively. The measurement results can also be modified according to the sensitivity coefficient of the strain gauge, wire resistance, bridge mode, and sensitivity of various bridge sensors. In this experiment, half bridge connection is used to measure.

2.3. Stress-Strain Study. Through experiments, transverse strain and volumetric strain data of eight groups of samples were obtained, and then the Origin software was used to draw the figure below. Figure 1 shows the axial stressstrain diagrams from sample A-1 to sample A-8.

In the whole process of stress-strain prepeak curve, axial strain, transverse strain, and volumetric strain all increase with the increase of stress. As for the postpeak curve, the stress is decreasing, and the axial strain, transverse strain, and volumetric strain are all increasing. It shows that after the peak point, the coal mass is in a state of failure, and 

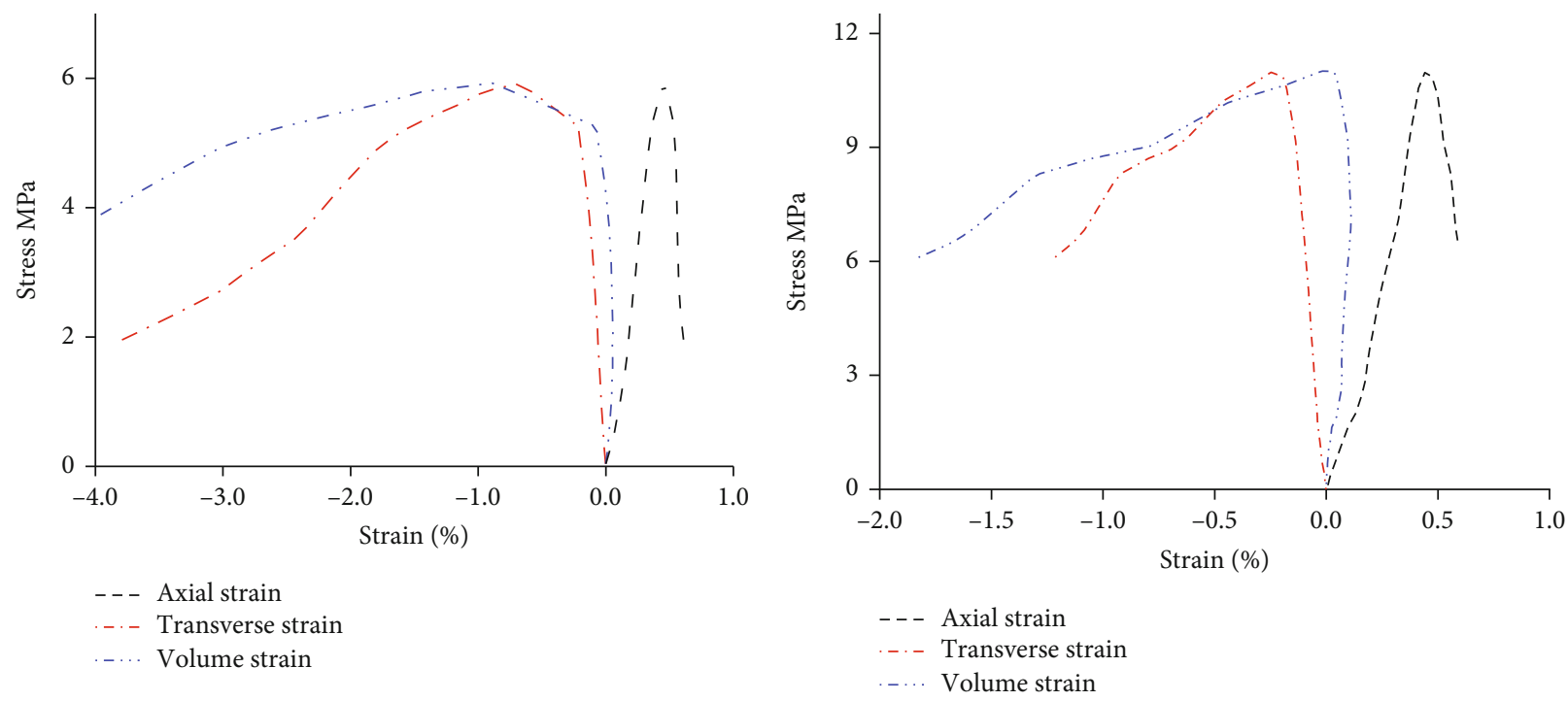

(a) A-1

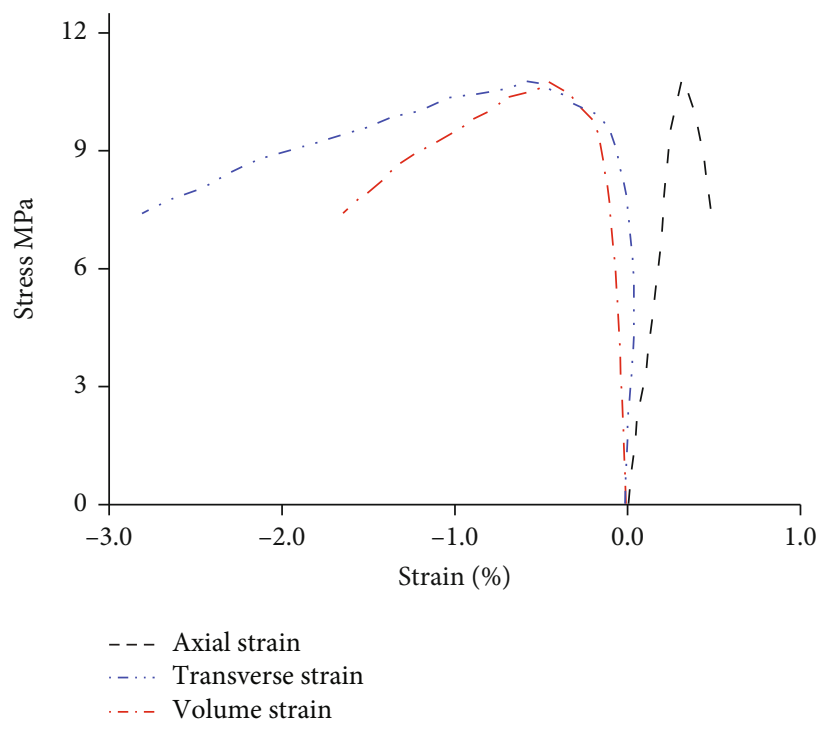

(c) A-3 (b) A-2

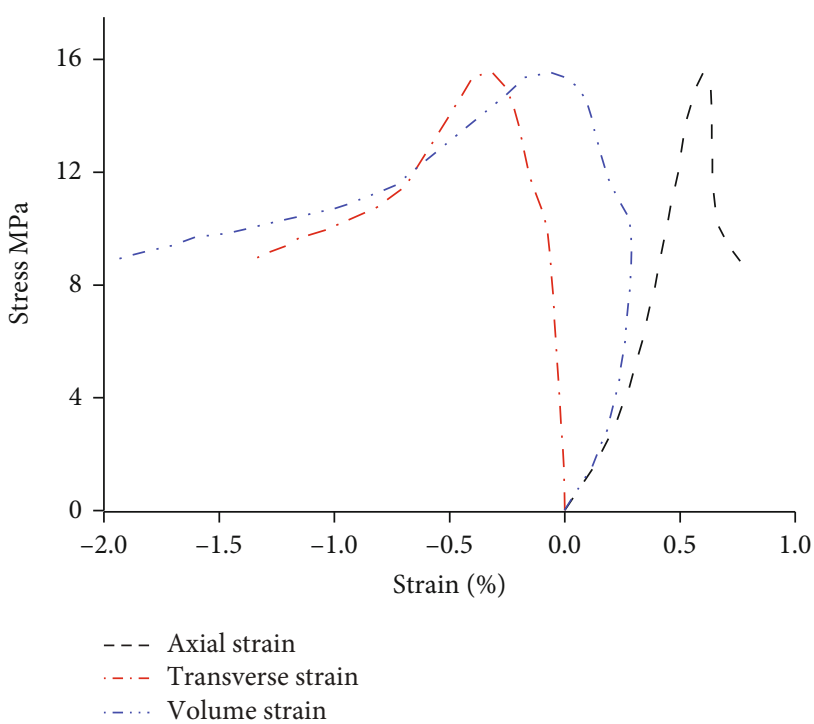

(d) A-4

Figure 1: Continued. 


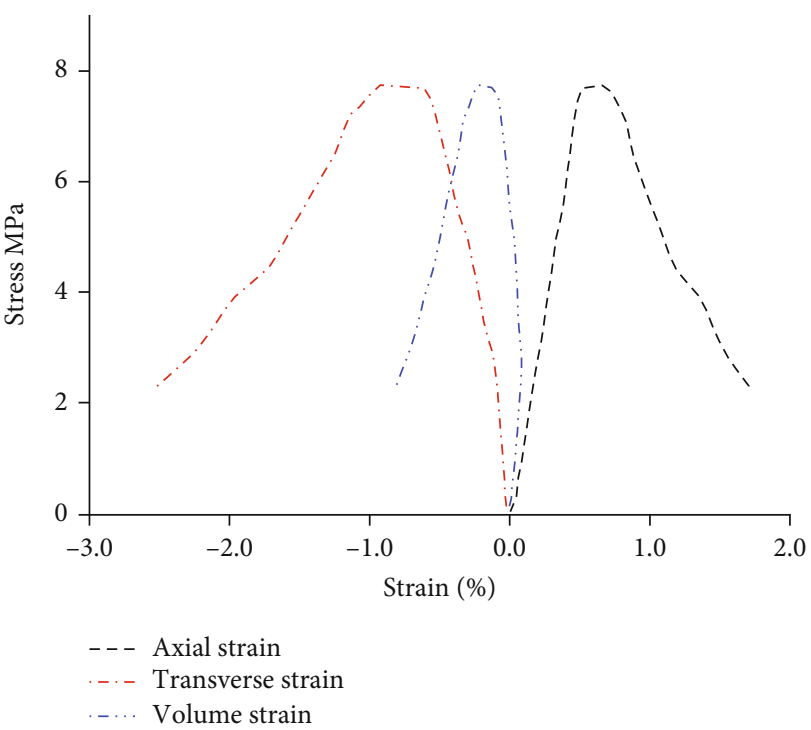

(e) A-5

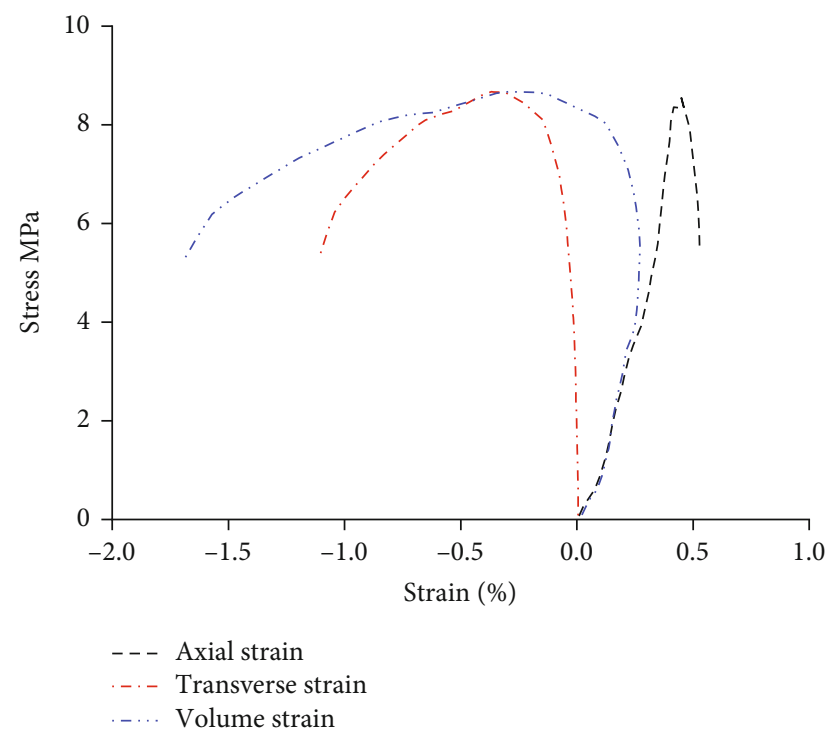

(g) A-7

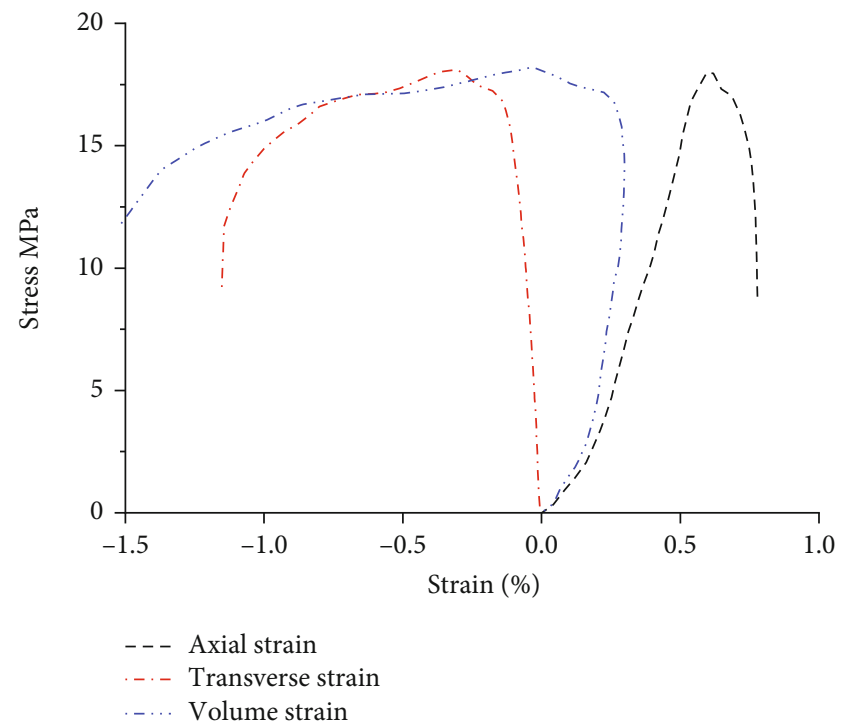

(f) A-6

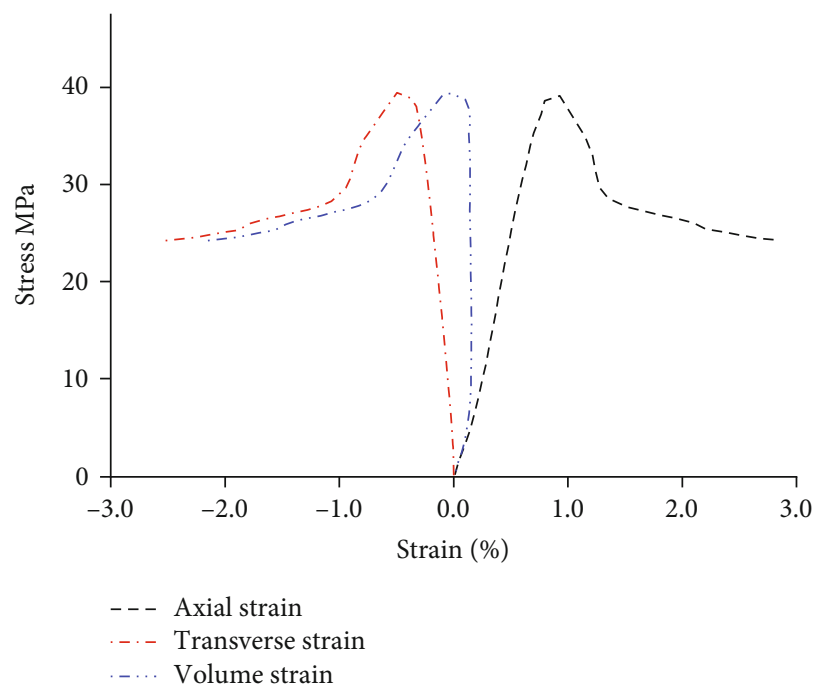

(h) A-8

Figure 1: Axial stress-axial strain diagrams.

the deformation cannot be restored, which is consistent with the experiment. Before the peak, the increment of volumetric strain is smaller than the increment of axial strain and transverse strain, and the deformation of volumetric strain is smaller than that of axial and transverse strain. From the point of view that the component is compressed, the axial direction of the component is in the state of compression, while the transverse direction of the component is in the state of stretching. As a whole, the volumetric strain is first positive and then negative, indicating that the volume of the component decreases slightly in the process of unidirectional compression and then increases slightly with the destruction of the component, which is consistent with the theory.

2.4. Volumetric Strain Study. The primary condition of the crack volume strain should meet the small deformation con- dition stipulated in "Elastic Mechanics," which represents the volume strain generated by plastic deformation and fracture [41-43]. The detailed derivation process is as follows.

The axial force $F$, axial deformation $\Delta l$, and circumferential deformation value $\Delta c$ bar of the whole process of rock loading and unloading failure can be obtained through the test.

The axial strain is [44]

$$
\varepsilon_{1}=\frac{\Delta l}{l},
$$

where $l$ is the height of sample before loading.

The circumferential strain is [45]

$$
\varepsilon_{2}=\frac{\Delta c}{c},
$$




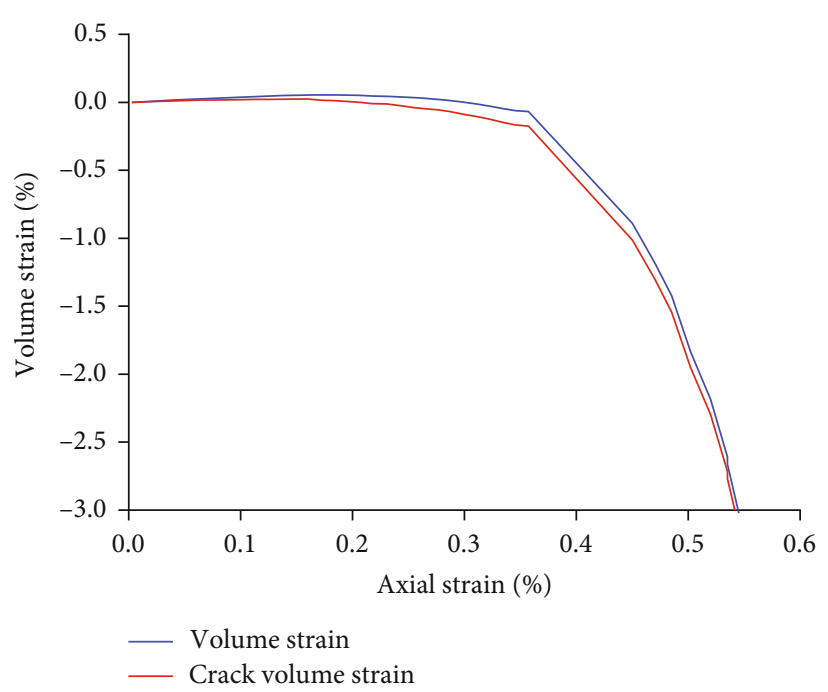

(a) A-1

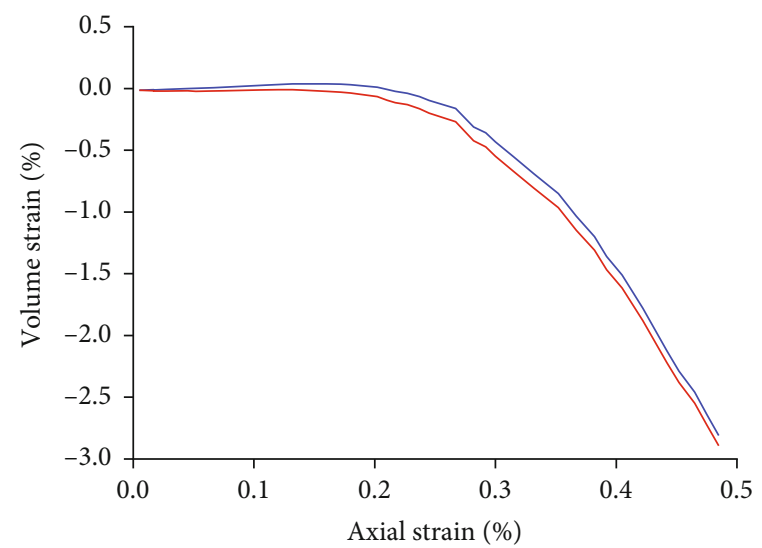

_ Volume strain

_ Crack volume strain

(c) A-3

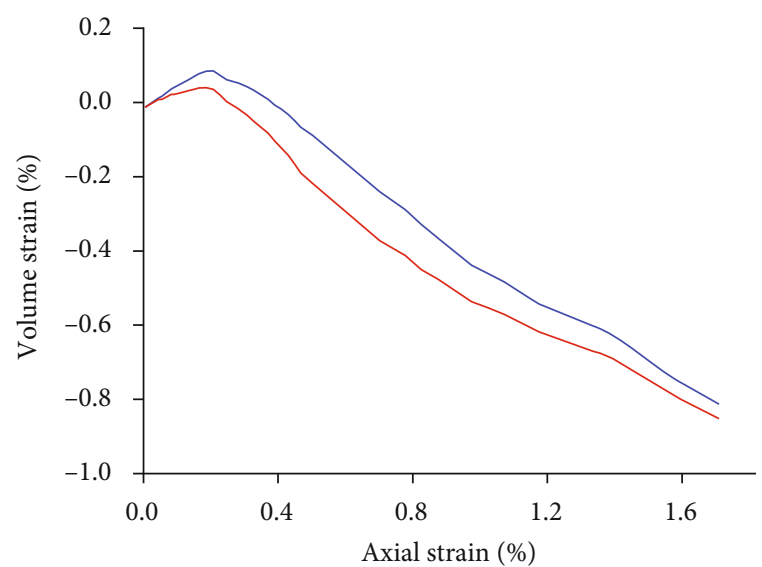

— Volume strain

_ Crack volume strain

(e) A-5

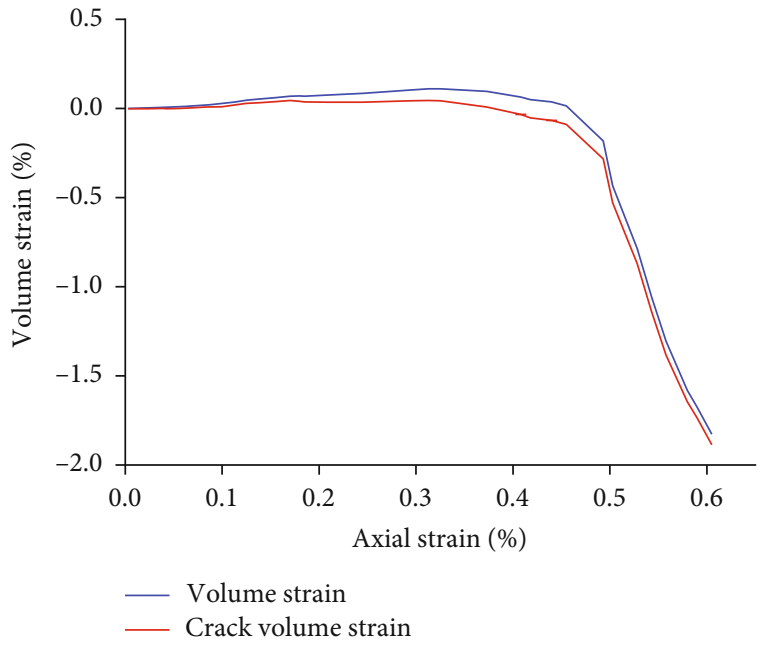

(b) A-2

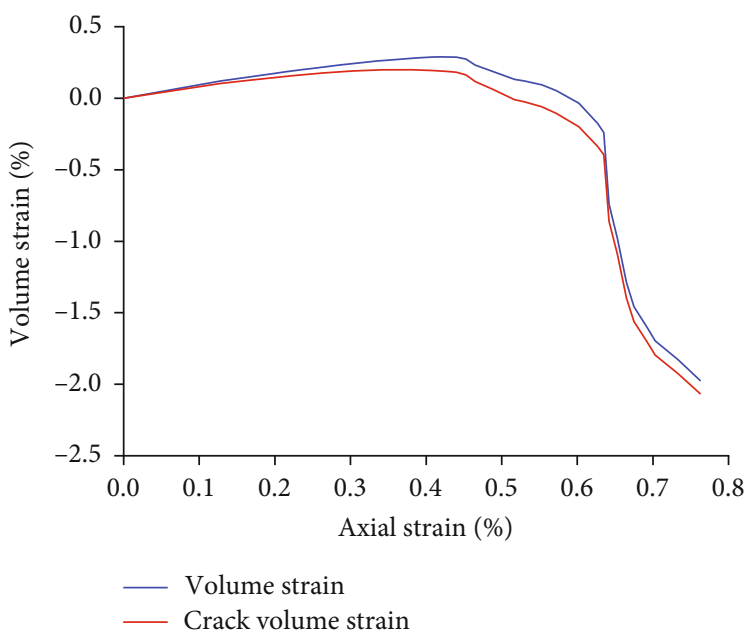

(d) A-4

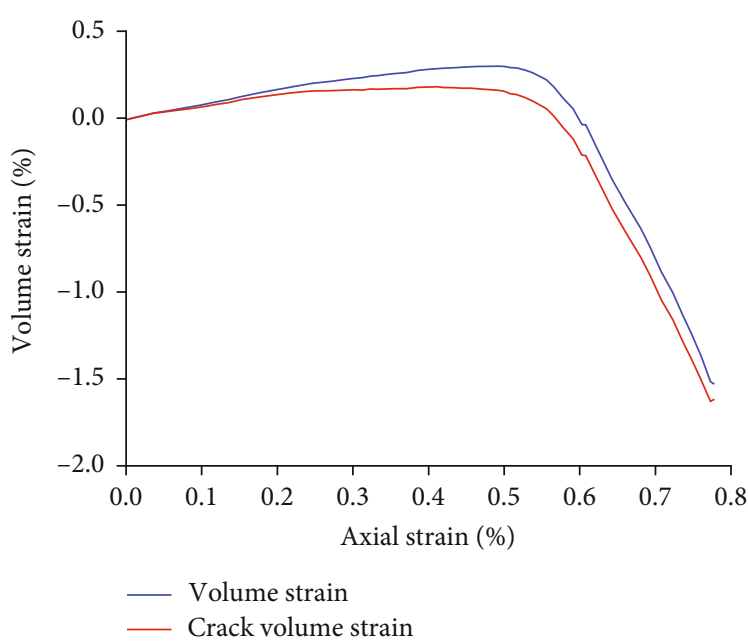

(f) A-6

Figure 2: Continued. 


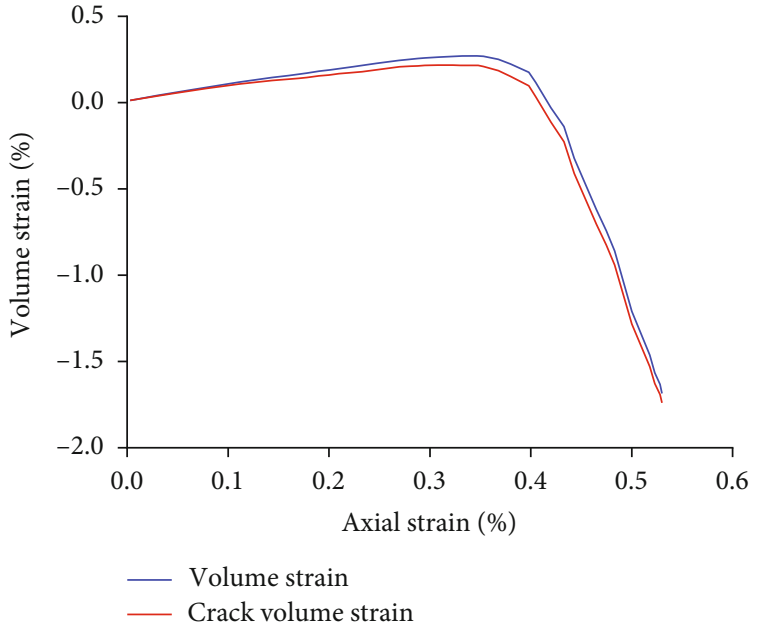

(g) A-7

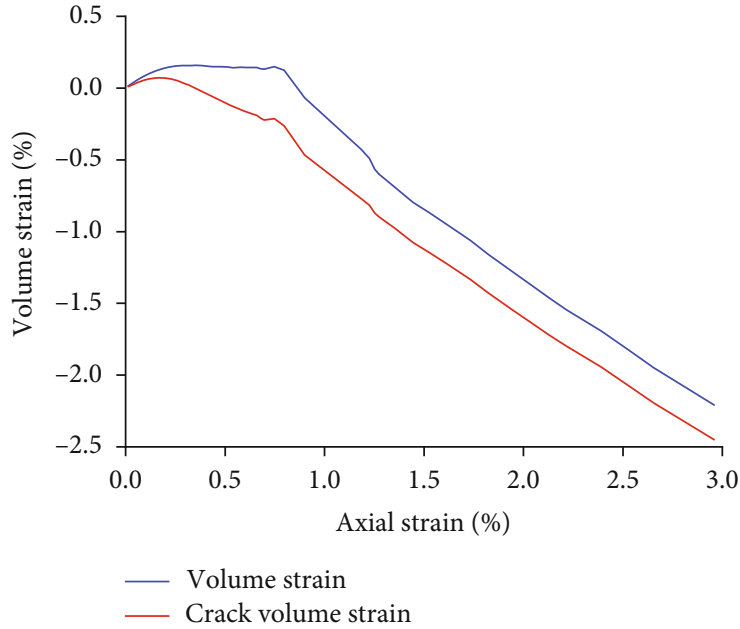

(h) A-8

FIGURE 2: Volume strain-axial strain and crack volume strain-axial strain.

where $\Delta c$ is the circumferential deformation, and $c$ is the circumferential perimeter of the sample before deformation.

The volume strain is

$$
\varepsilon_{v}=\varepsilon_{1}+2 \varepsilon_{2}
$$
is

The volume strain of the crack of the circular specimen

$$
\varepsilon_{c v}=\varepsilon_{v}+\varepsilon_{e v},
$$

where $\varepsilon_{c v}$ is the crack volume strain of the rock sample, and $\varepsilon_{e v}$ is the projectile strain of the rock sample.

According to Hooke's Law:

$$
\begin{gathered}
\varepsilon_{e 1}=\frac{1}{E}\left[\sigma_{1}-v\left(\sigma_{2}+\sigma_{3}\right)\right], \\
\varepsilon_{e 2}=\frac{1}{E}\left[\sigma_{2}-v\left(\sigma_{1}+\sigma_{3}\right)\right],
\end{gathered}
$$

where $\varepsilon_{e 1}$ is the axial elastic strain of the rock sample, and $\varepsilon_{e 2}$ is the circumferential elastic strain of rock sample.

For the conventional triaxial test, due to $\sigma_{2}=\sigma_{3}$

$$
\varepsilon_{c v}=\varepsilon_{v}-\frac{(1-2 v)\left(\sigma_{1}+2 \sigma_{3}\right)}{E}
$$

The equivalent plastic strain is

$$
\varepsilon_{e p}=\frac{\sqrt{2}}{3} \sqrt{\left(\varepsilon_{1 p}-\varepsilon_{2 p}\right)^{2}+\left(\varepsilon_{2 p}-\varepsilon_{3 p}\right)^{2}+\left(\varepsilon_{1 p}-\varepsilon_{3 p}\right)^{2}},
$$

where $\varepsilon_{1 p}, \varepsilon_{2 p}, \varepsilon_{3 p}$ are plastic strain in three principal stress directions.

The above parameters were calculated from the experimental data, and Origin software was used to draw equivalent plastic strain-axial strain curve, as shown in Figure 2.
The analysis of the volume strain and crack volume strain shows that although the volume strain curve of the crack is close to volume strain curve, but it is always lower than the volume strain curve. In accordance with the physical meaning of crack volume strain, that is, under the condition of small deformation, the volume strain curve of the crack is similar to that of the volume strain. Through the study of crack volume strain, the degree and law of coal rock cracking can be further explained, which has certain guiding significance for coal mining.

2.5. Failure Process Analysis of Rock Samples. Based on the test data, volumetric strain-axial strain diagrams were drawn by software, and the failure of coal mass was analyzed by combining the graph with the test site situation.

According to Figure 3, coal mass experiences 6 stages from initial pressure to failure and then to residual deformation, and these six stages also show the nonlinear elastic behavior of rock. Because there are many small pores, cracks, and other defects in the rock, the stress-strain curve of rock under pressure is not linear, but nonlinear. The specific analysis is as follows:

(1) Crack Closure Stage (A-B in the Figure). From the volume strain-axial strain curve of crack, it can be seen that there are natural cracks in the coal mass, and because of the external pressure, the natural cracks are constantly closed. When they reach point A, the natural cracks are completely closed, and the strain of the crack body tends to be 0

(2) The Elastic Stage (B-C in the Figure). The volumetric strain of the crack is basically unchanged, and no new fracture occurs inside the rock. If the load is removed at this time, the coal mass will return to the original state, so this stage is called the elastic stage. Meanwhile, this relationship is linear elastic relationship 


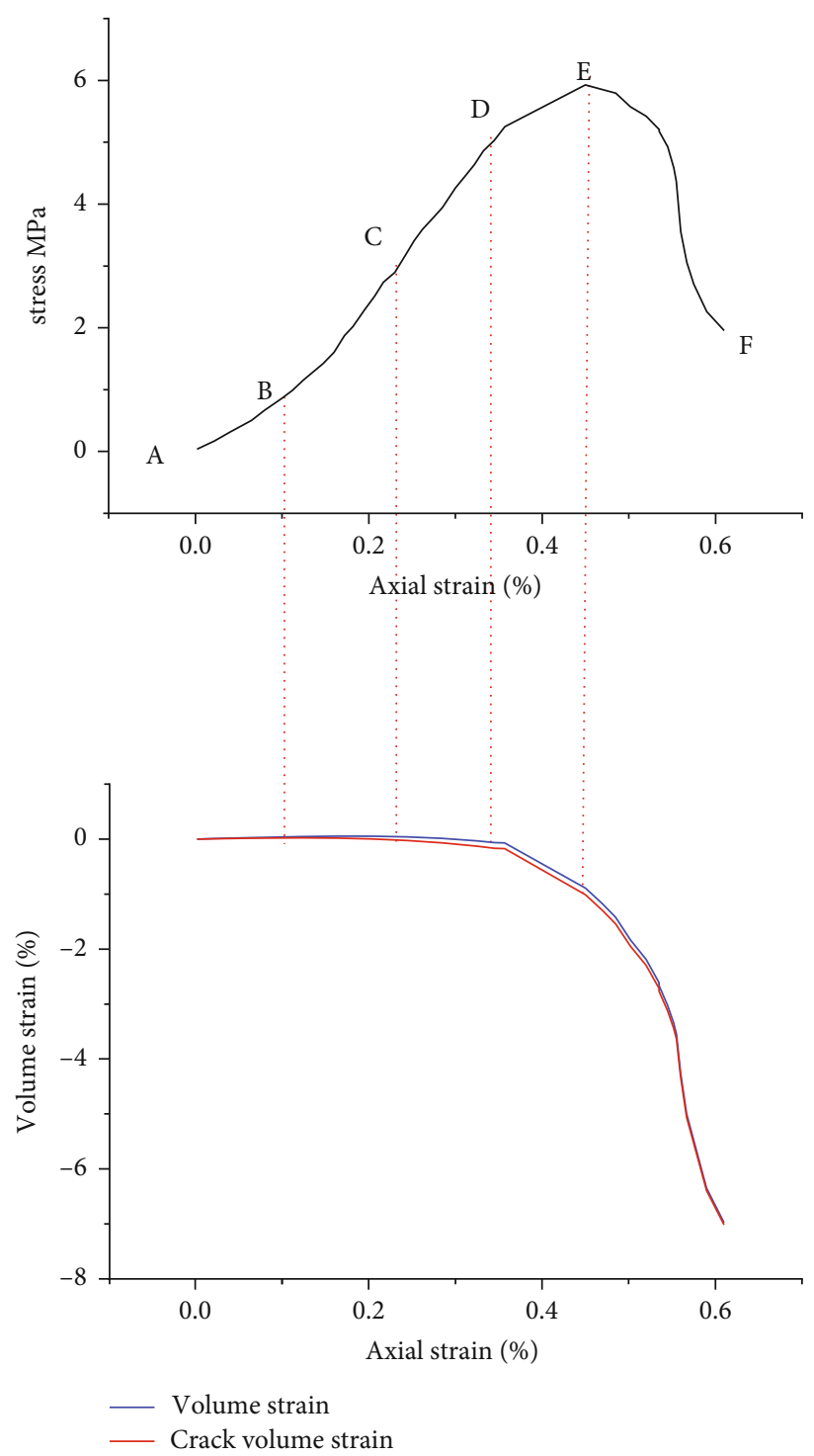

(a) A-1
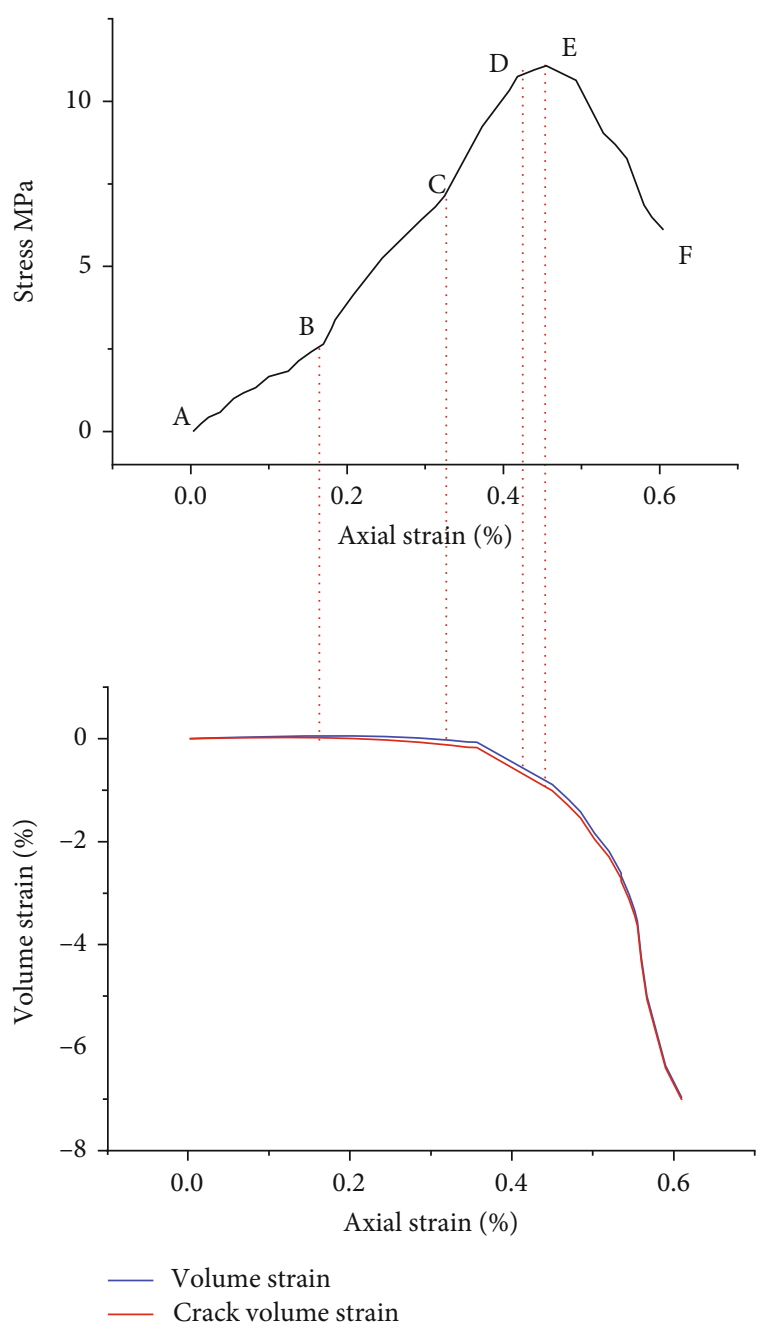

Figure 3: Continued. 

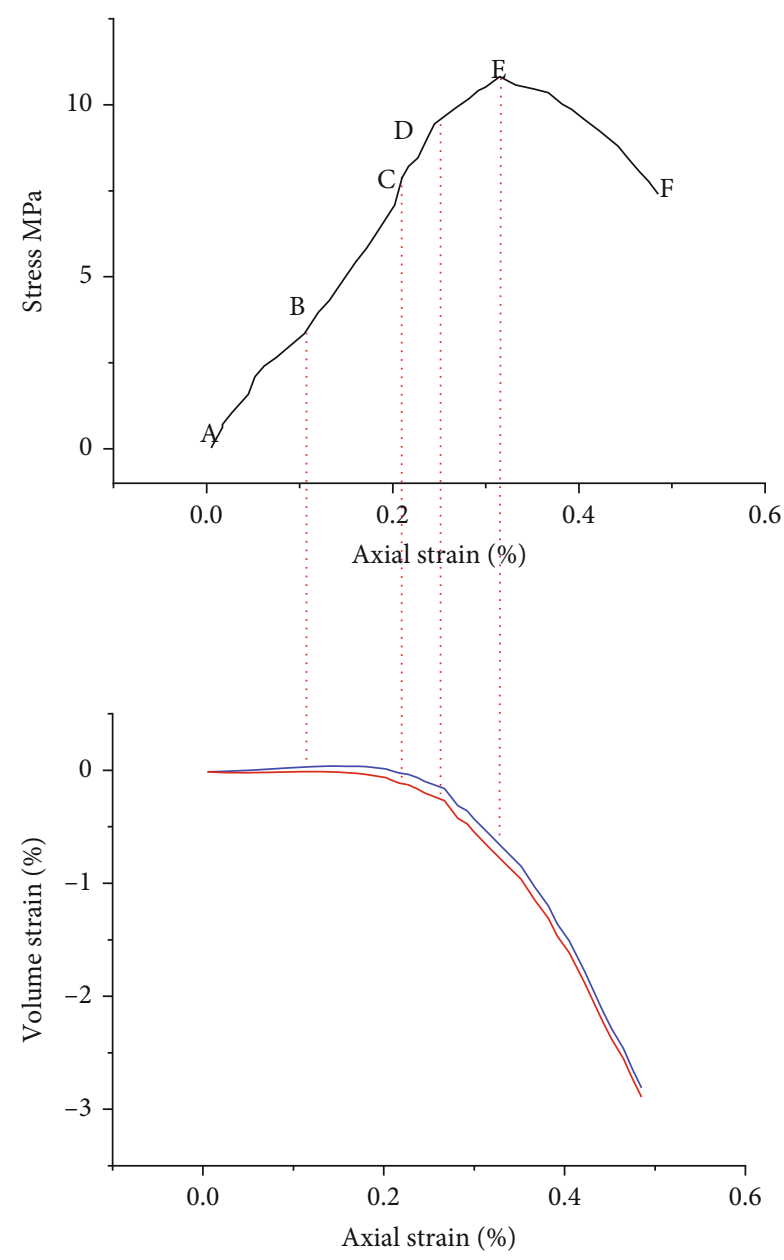

- Volume strain

Crack volume strain

(c) A-3

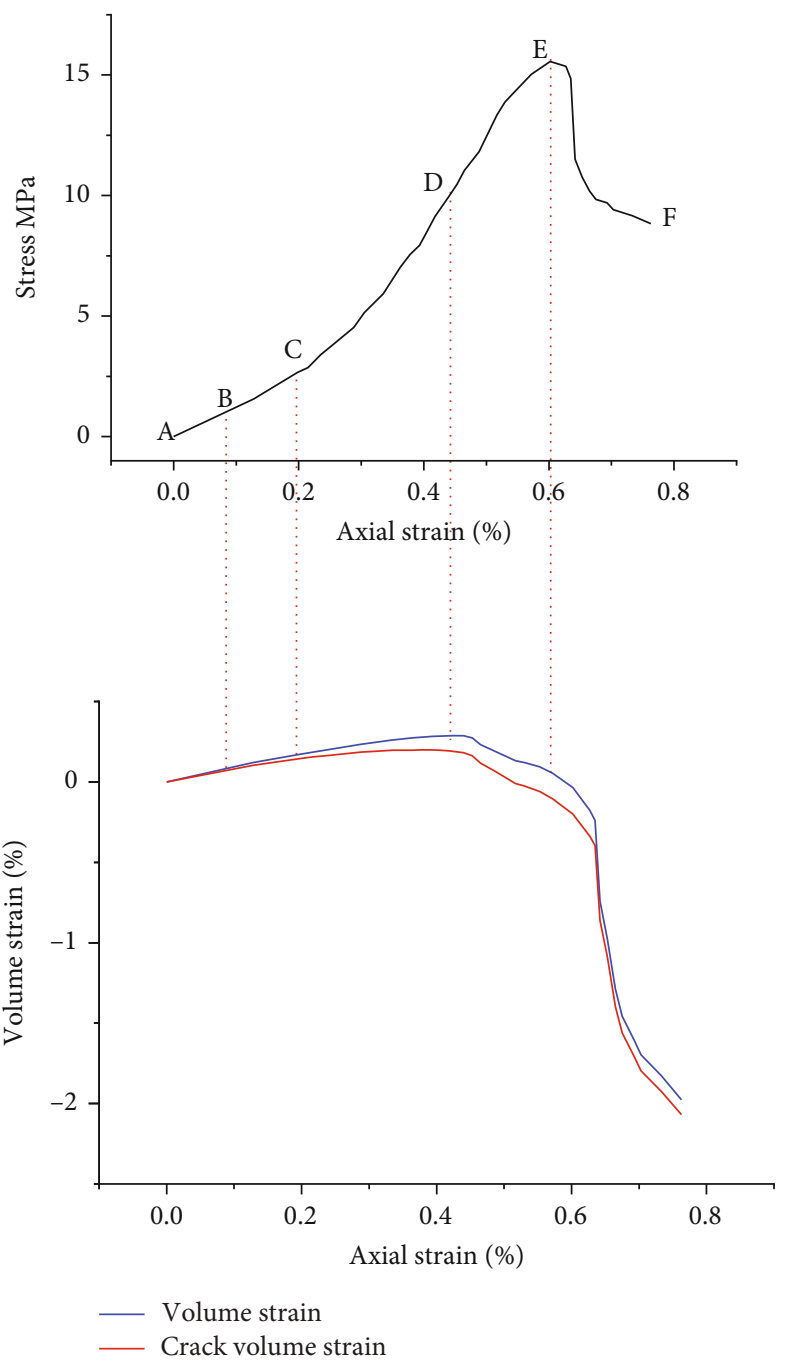

(d) A-4

Figure 3: Continued. 


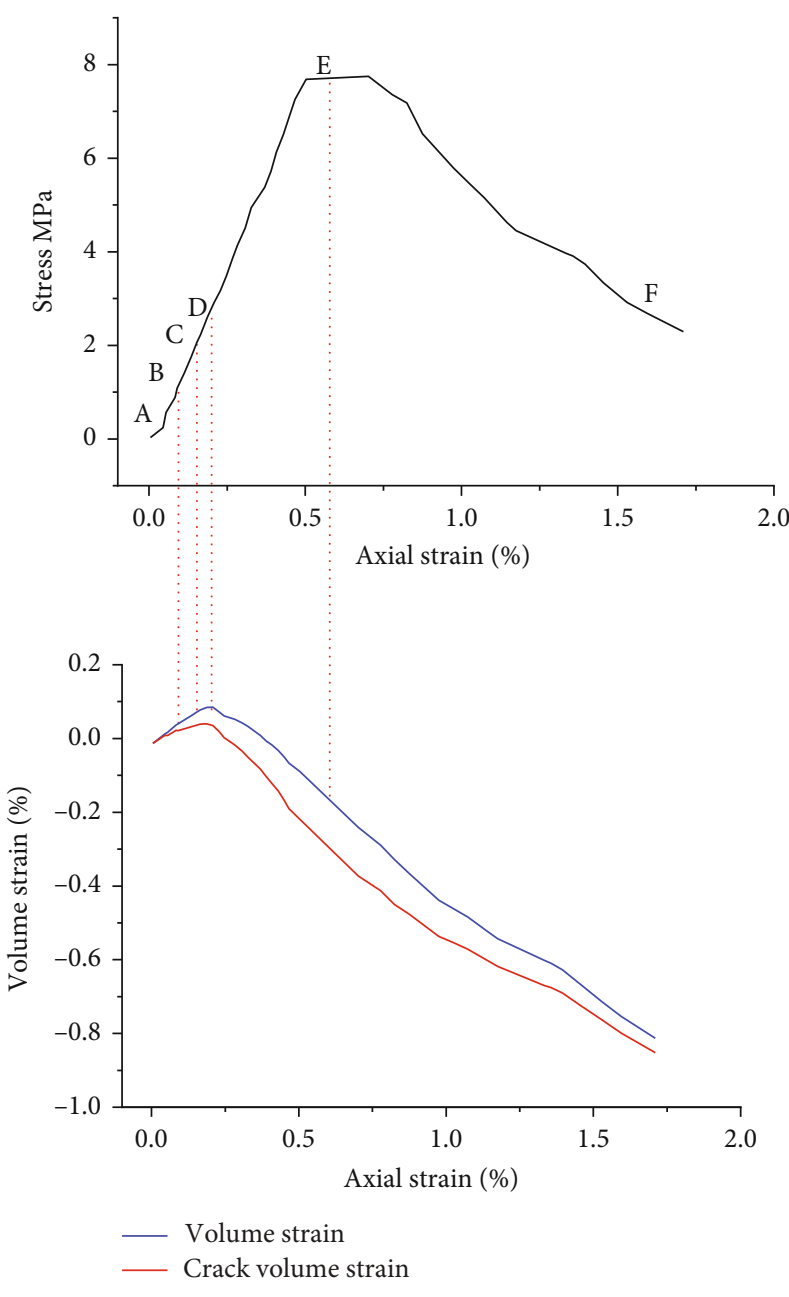

(e) A-5
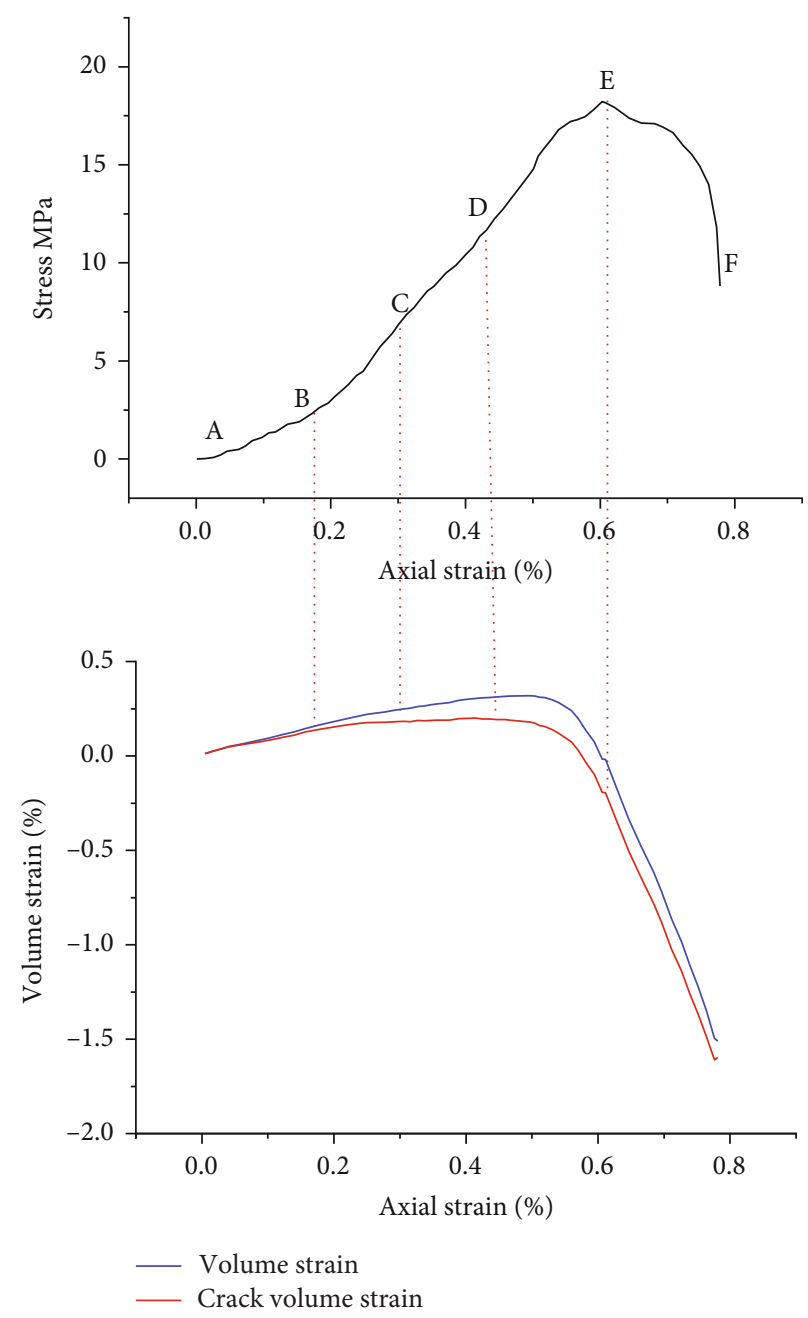

(f) A-6

Figure 3: Continued. 


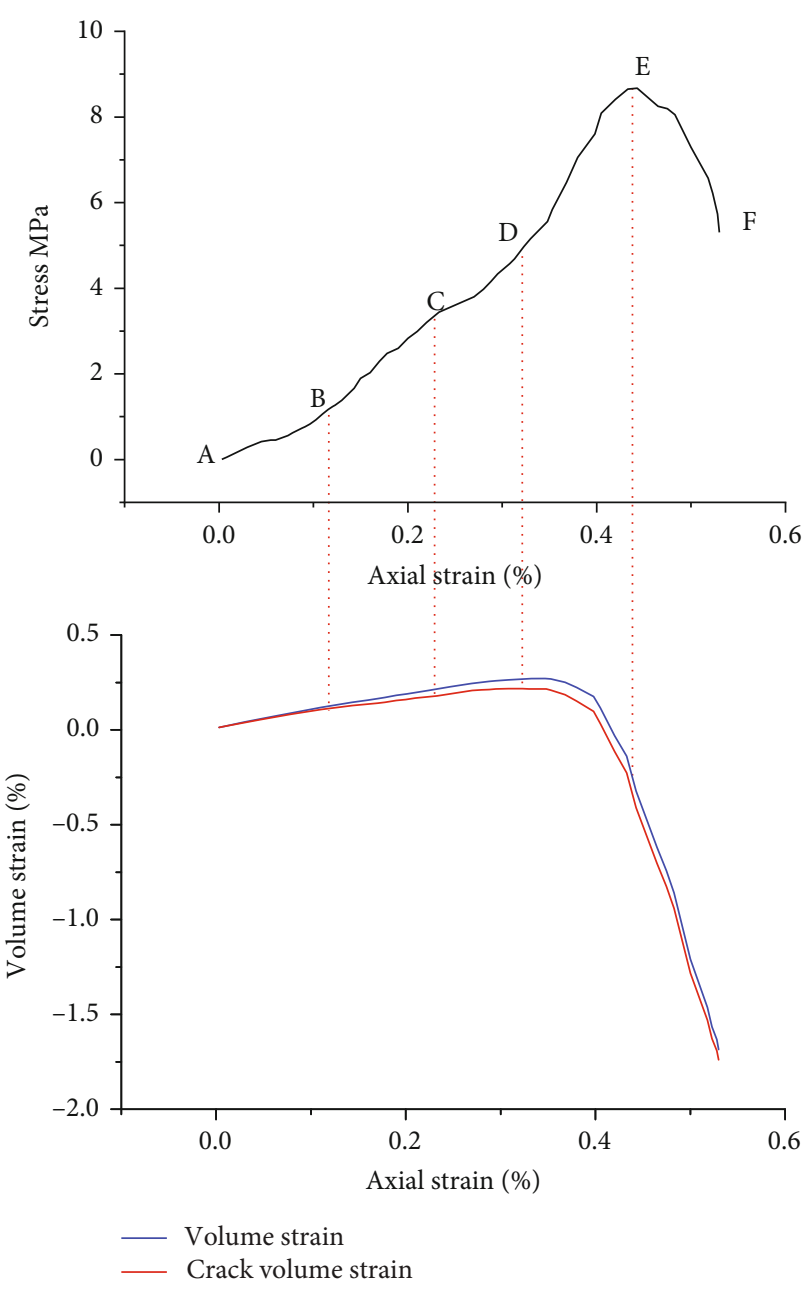

(g) A-7

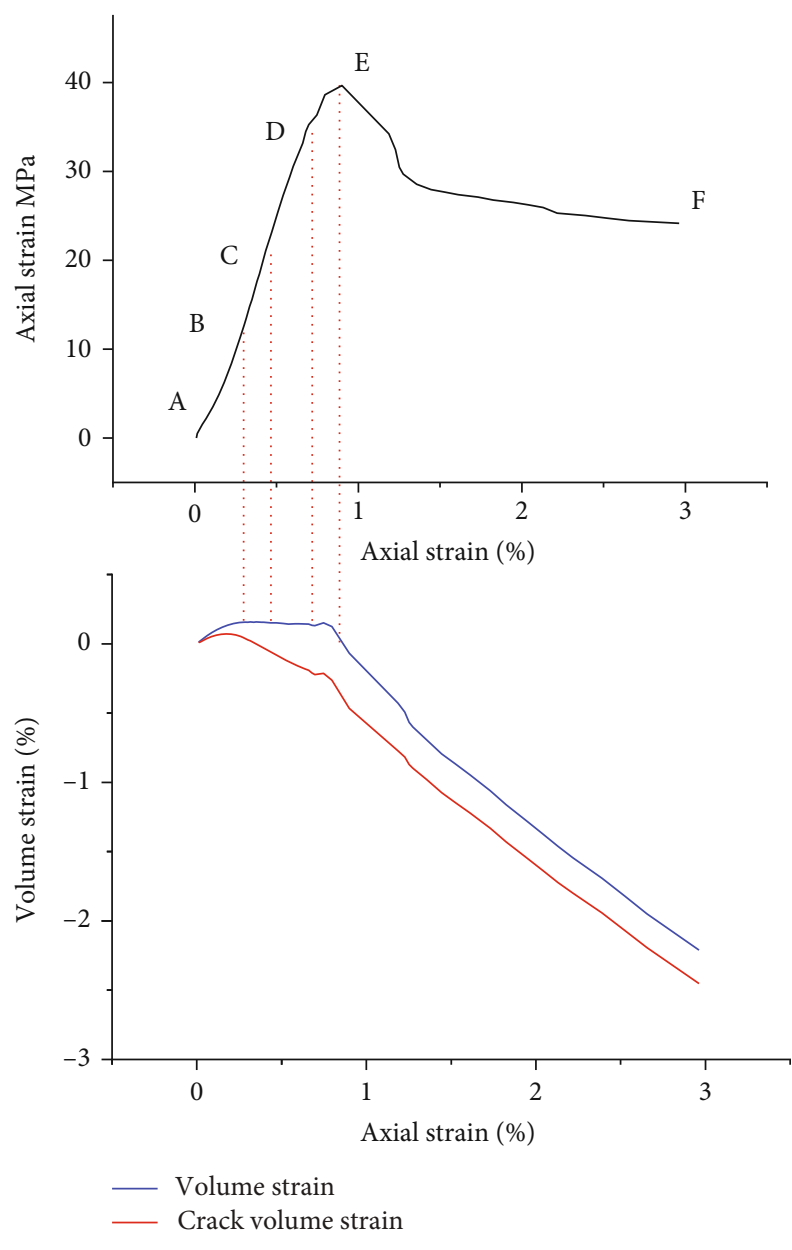

(h) A-8

FIGURE 3: Stress-axial strain, volumetric strain-axial strain, and crack volume strain-axial strain.

(3) Tension Crack Development Stage (C-D in the Figure). New cracks begin to appear in the interior of coal mass, damage also begins to occur, and the volume strain of cracks keeps increasing. At this stage, the slope of volume strain-axial strain of the crack is low because the damage increase rate is relatively small. The failure process of rock samples is that the tensile cracks are generated first, and the shear failure is caused by the interaction of tensile cracks. Therefore, it can be considered that the stage (C-D section) when the crack volume strain begins to increase until the sudden change of volume strain occurs is the tensile failure inside the coal mass

(4) Macrocrack Development Stage (D-E in the Figure). When it reaches point $\mathrm{D}$, the volume strain of coal mass changes abruptly, the slope of the volume strain curve of crack increases, the rate of damage increases, and the axial stress-strain curve begins to flatten. Therefore, it can be considered that at point $\mathrm{D}$, tensile cracks run through each other and form macroscopic cracks. The stage after point $\mathrm{D}$ can be considered as the development stage of macroscopic crack, and the coal mass changes from macroscopic continuous state to discontinuous state. However, the macrofailure mode of coal mass is determined by the interaction of tensile cracks, and pressure plays a certain control role on the interaction of tensile cracks, so pressure plays a control role on the macro-failure mode of coal mass

(5) Rock Structural Stage (E-F in the Figure). When it reaches point $\mathrm{F}$, the axial strain of coal mass reaches the maximum. At this time, because of the penetration of macro cracks, coal mass can no longer be regarded as rock material, and coal mass bears load with rock structure. The postpeak stress-strain response of coal mass is not only related to the material properties and the macroscopic failure mode but also related to the stiffness of the test machine. This is because the postpeak behavior of rock is the coordination between rock structure and external forces tends to be stable 


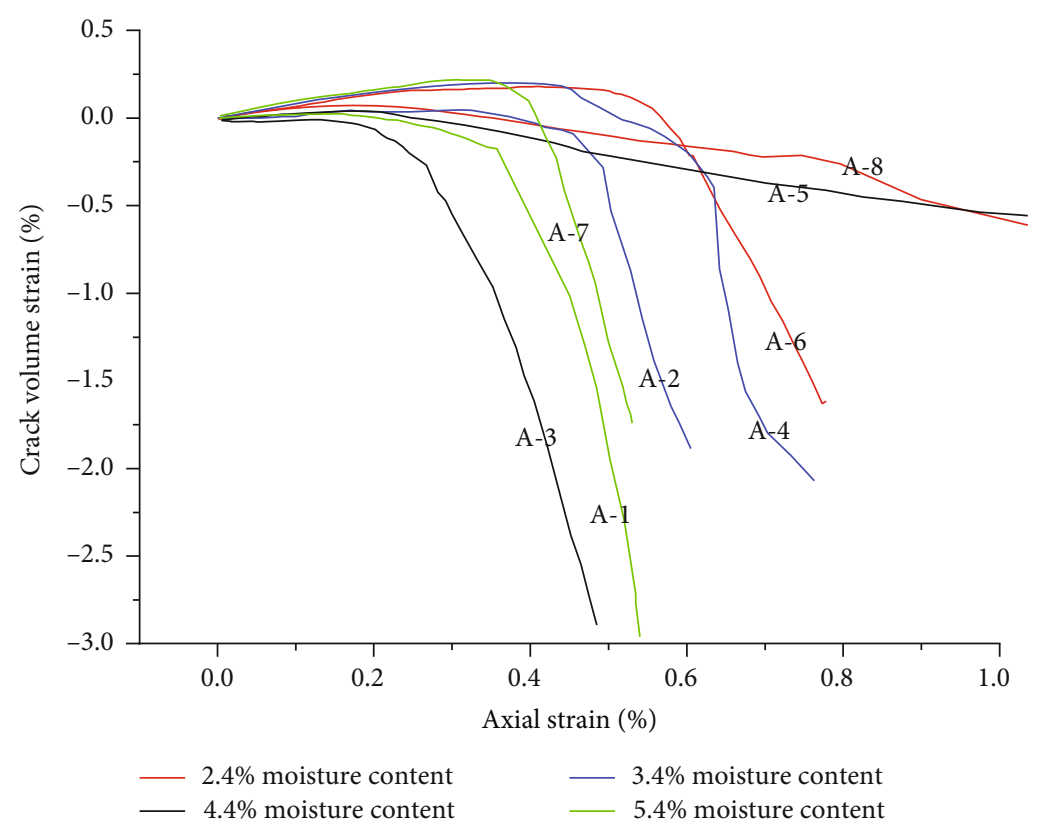

FIGURE 4: Volume strain-axial strain diagram of crack under different water content.

(6) Residual Strength Stage (after F in the Figure). When it reaches point $\mathrm{F}$, the damaged coal mass forms a stable rock structure and rock structure reaches a state of equilibrium. Therefore, the residual strength is shown on the axial stress-strain curve. The slope decreases at point $\mathrm{F}$ on the equivalent plastic strain-axial strain curve, indicating that the growth rate of the equivalent plastic strain decreases at point $\mathrm{F}$, and the rock structure tends to be relatively stable and enters the residual strength. The volumetric strain slightly decreases after reaching point $\mathrm{F}$, indicating that the rock structure tend to be stable

Figure 4 shows the volumetric strain-axial strain diagram of the crack under different water content, from which it can be concluded:

(1) The volumetric strain-axial strain graphs of cracks with different water content have basically the same variation rule. The volume strain of the crack increases slightly at first and then decreases continuously. This is because at the beginning of pressure, the natural cracks in coal begin to close in the crack closure stage, and the crack volume strain approaches 0 at this time. In the subsequent elastic stage, the volume strain of the crack is basically unchanged. During the tensile crack development stage, new cracks appear and the volume strain of cracks begins to increase. At the macrocrack development stage, the slope of the crack increases and begins to decrease

(2) The larger the moisture content is, the more rapidly the curve of the crack changes from the beginning to the residual strength. Because the higher the moisture content is, the more cracks in the coal mass are, the weaker the ability to resist deformation is, and the faster it reaches the stage of residual strength

\section{Study on Brittleness Index of Coal Mass}

Brittleness is a physical attribute of coal mass, which is related to the mineral composition and stress action of coal mass [46-48]. Reservoir rock brittleness is mechanical properties evaluation, borehole wall stability evaluation, and the important indexes for evaluation of hydraulic fracturing effect. It has a good reference value for the safety analysis of rock engineering under the coupling effect of stress and seepage [49]. Although there is no unified standard of rock brittleness definition and testing method, but low strain or damage and fracture of tensile fracture damage, highpressure ratio, high resilience, and after peak stress drop quickly recognized as is shown by the nature of the rock brittleness $[50,51]$. The following are several common methods of brittleness evaluation.

3.1. Curve Method. Curve method is a brittleness evaluation method established according to each stage corresponding to axial stress-strain curve [52]. Thus, establishing the brittleness index

$$
B_{7}=\frac{\sigma_{p}-\sigma_{r}}{\sigma_{p}},
$$

where $\sigma_{p}$ and $\sigma_{r}$ are the peak stress and residual stress, respectively.

Based on the experimental data and the formula of the brittleness index $B_{7}$, the image of the brittleness index $B_{7}$ under the different water content is made. As shown in Figure 5 , the greater the value of $B_{7}$, the stronger the brittleness of coal. It can be seen from the above figure that from 


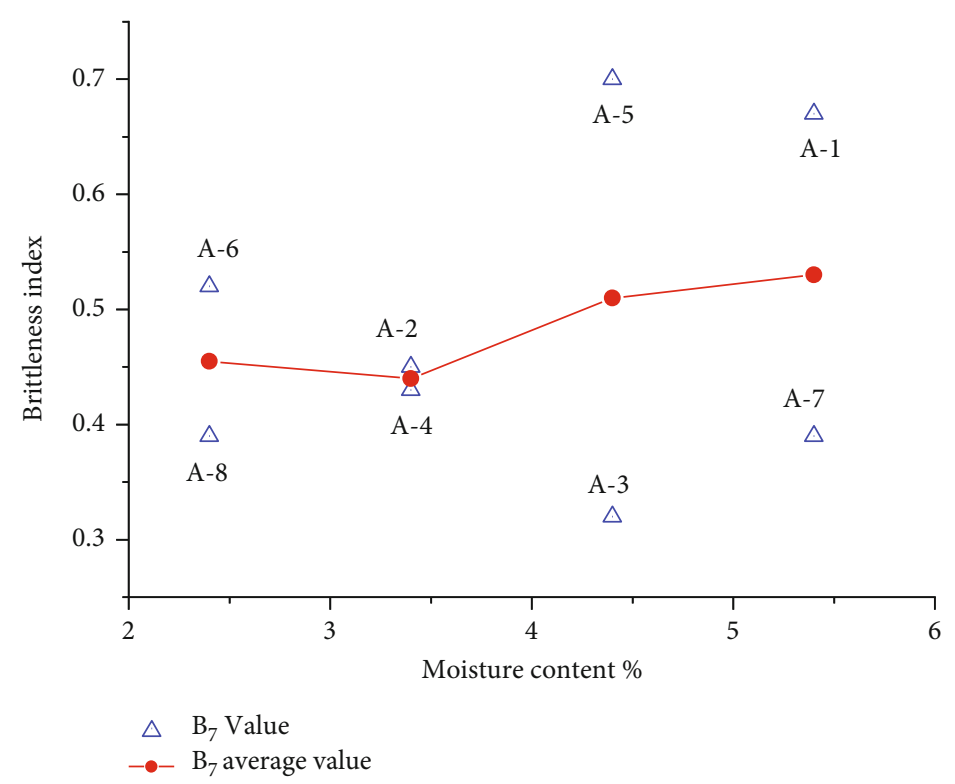

FIGURE 5: $B_{7}$ under different conditions.

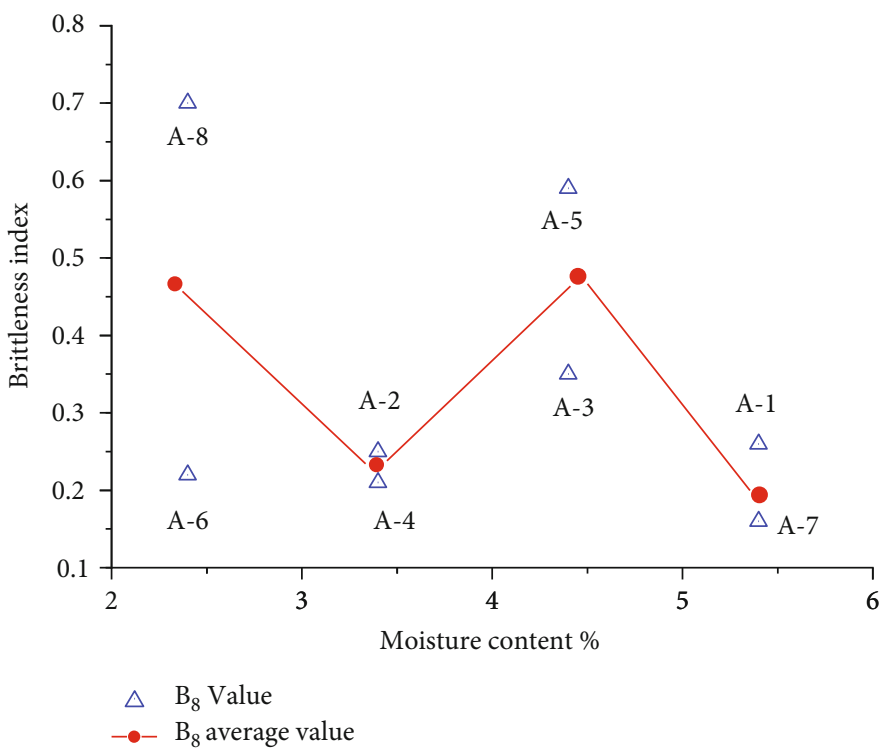

Figure 6: $B_{8}$ at different water content.

the $B_{7}$ value of each pattern, the $B_{7}$ value of A-5 with water content of $4.4 \%$ is the largest, and the brittleness is stronger, followed by A-1 with water content of $5.4 \%$. From the mean value of the pattern, the pattern with water content of $5.4 \%$ has the highest $B_{7}$ value and the strongest brittleness, followed by the pattern with water content of $4.4 \%$.

It is considered that the smaller the difference between the strain in which the friction strength reaches the maximum value (i.e., the peak strain) and the strain in which the cohesion weakens to the residual value (i.e., the residual strain)

$$
B_{8}=\frac{\varepsilon_{r}-\varepsilon_{p}}{\varepsilon_{r}},
$$

where $\varepsilon_{p}$ and $\varepsilon_{r}$ are the peak strain and residual strain, respectively.

According to the test data and the formula of $B_{8}$, the image of $B_{8}$ with different water content is made by Origin software. According to Figure 6, the smaller the value of $B_{8}$ is, the stronger the brittleness of coal mass will be. From the $B_{8}$ value of each pattern, the $B_{8}$ value of $\mathrm{A}-7$ with water content of $5.4 \%$ is the smallest, and the brittleness of coal is stronger, followed by A-4 with water content of $3.4 \%$. From the average $B_{7}$ value of the pattern, the pattern with water content of $5.4 \%$ has the smallest value and the strongest brittleness, followed by the pattern with water content of $3.4 \%$. 


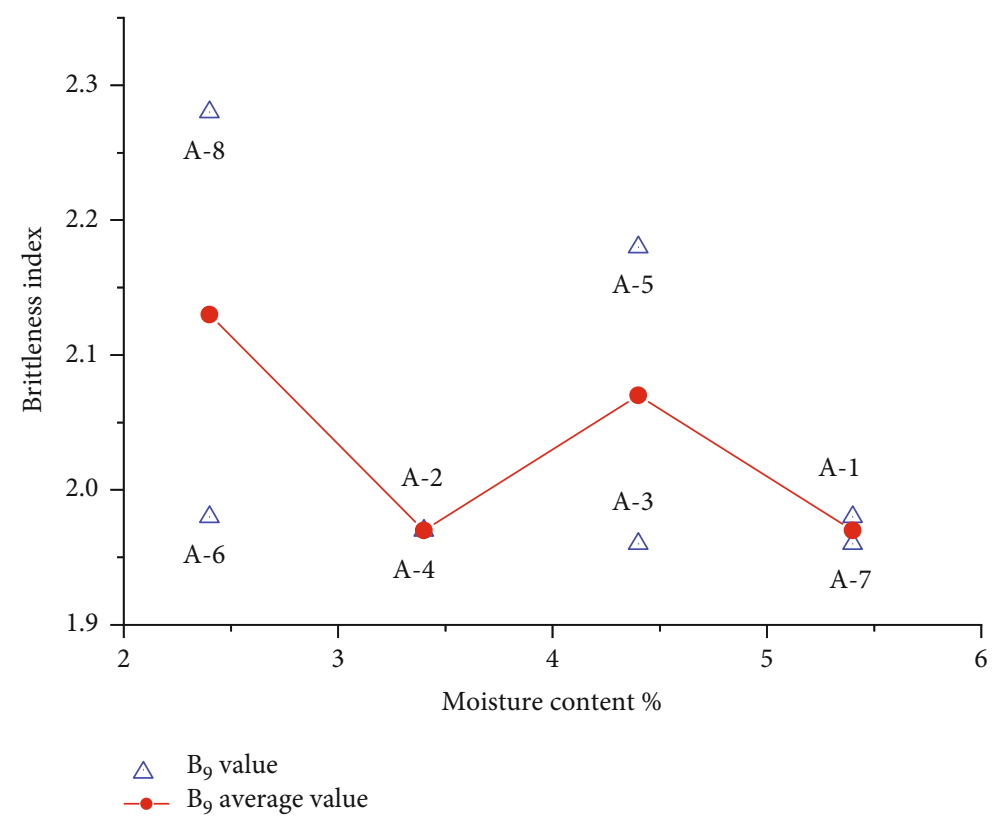

FIgURE 7: $B_{9}$ under different water content.

On the basis of summarizing the previous studies, a brittleness index which considered the mechanical characteristics of pre- and postpeak simultaneously.

$$
\begin{gathered}
B_{9}=B_{9}^{\prime}+B_{9}^{\prime \prime}, \\
B_{9}^{\prime \prime}=\alpha C_{S}+\beta C_{S}+\eta, \\
C_{S}=\frac{\varepsilon_{p}\left(\sigma_{p}-\sigma_{r}\right)}{\sigma_{p}\left(\varepsilon_{r}-\varepsilon_{p}\right)},
\end{gathered}
$$

where $\alpha, \beta$, and $\eta$ are the standardization coefficient, and $C_{S}$ is the ratio of the absolute value of the postpeak curve slope to the prepeak curve slope.

According to the test data and the formula of $B_{9}$, the image of $B_{9}$ under different water content is made by Origin software. According to Figure 7, the $B_{9}$ value of A-3 and A-7 is the smallest, which is 1.96 . The value $B_{9}$ of A-8 is the largest, 2.28. It indicates that the brittleness of $\mathrm{A}-3$ and $\mathrm{A}-7$ is the strongest, while that of A-8 is the least. The average brittleness index with the water content of $3.4 \%$ is the smallest, and the brittleness is stronger. The average brittleness index of $2.4 \%$ is the largest and the weakest.

We studied the brittleness index

$$
\begin{gathered}
B_{10}=B_{10}^{\prime} B_{10}^{\prime \prime}, \\
B_{10}^{\prime}=\frac{\sigma_{p}-\sigma_{r}}{\sigma_{p}}, \\
B_{10}^{\prime \prime}=\frac{\lg \left|K_{a c}\right|}{10},
\end{gathered}
$$

where $K_{a c}$ is the slope of the postpeak curve. The higher the value of $B_{10}$, the higher the degree of brittleness.
According to the test data and the formula of $B_{10}$, the image of $B_{10}$ is made by Origin software. As shown in Figure 8, the greater the value of $B_{10}$ is, the stronger the brittleness of coal mass is. From the $B_{10}$ value of each pattern, the $B_{10}$ value of A-1 with water content of $5.4 \%$ is the largest, and the brittleness of coal mass is stronger, followed by A-4 with water content of $3.4 \%$. From the average $B_{10}$ value of the pattern, the $B_{10}$ value of the pattern with water content of $3.4 \%$ and $5.4 \%$ is equal and the largest, and the brittleness is the strongest.

3.2. Energy Method. The brittleness index is established by using the energy relation expressed by the axial stressstrain curve [53-55], which corresponds to the energy change of coal mass during the compression process. It defines the brittleness index by the ratio of

$$
B_{11}=\frac{A_{2}}{A_{1}}
$$

where $A_{2}$ is defined as the recoverable energy (the area of BCD in Figure 9), and $A_{1}$ is defined as the total energy (the area of the OABD region in Figure 9). The greater the value of $B_{11}$ is, the greater the recovery elastic energy and brittleness will be. Figure 9 shows a diagram of brittleness index $B_{11}$ of coal.

According to the test data and the formula of $B_{10}$, the image of $B_{11}$ under different water content is made by Origin software. Analysis: as shown in Figure 10, the greater the value of $B_{11}$, the greater the recovery elastic energy, and the stronger the brittleness of coal. From the $B_{11}$ value of each pattern, A- 6 with water content of $2.4 \%$ has the largest $B_{11}$ value, and the brittleness is stronger, followed by A-3 with water content of $4.4 \%$. From the average $B_{11}$ value of the pattern, the pattern with $2.4 \%$ water content has the 


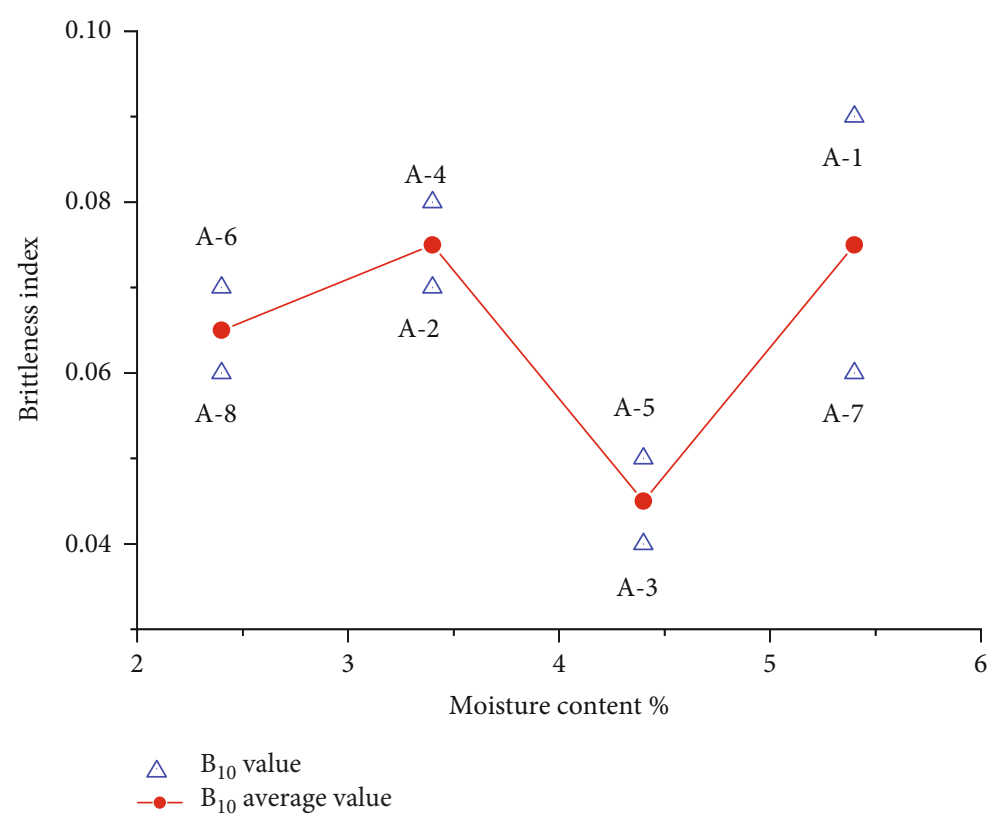

Figure 8: $B_{10}$ under different water content.

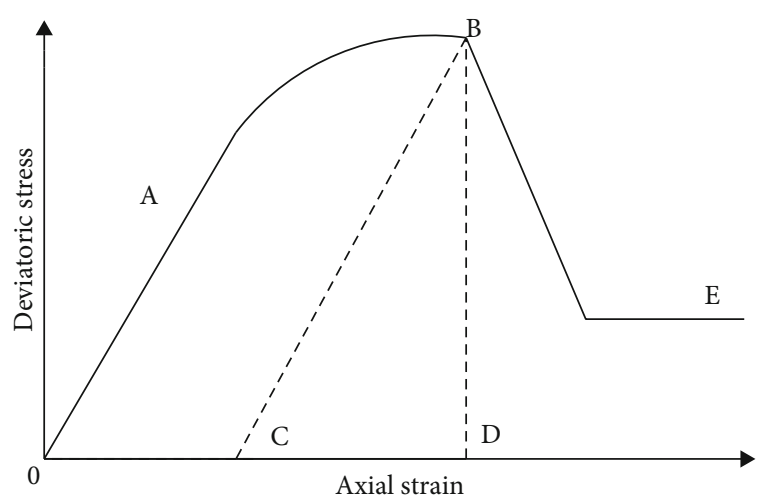

Figure 9: Schematic diagram of brittleness index $B_{11}$.

largest value and the strongest brittleness, followed by the pattern with $3.4 \%$ water content.

Tarasov et al. also considered the energy of postpeak process and proposed using the ratio of postpeak fracture energy to postpeak recoverable elastic energy as the brittleness index.

$$
B_{12}=\frac{d_{w r}}{d_{\mathrm{we}}},
$$

where $d_{w r}$ is defined as the postpeak rupture energy (the gray area on the right and in Figure 11), and $d_{\text {we }}$ is defined as the elastic energy behind the peak (the difference between the area of the large red triangle on the left of Figure 11 and the small red triangle on the right of Figure 11). The lower the value of $B_{12}$, the more brittle the rock is. Figure 11 shows a diagram of brittleness index $B_{12}$ of coal.
According to the test data and the formula of $B_{10}$, the image of $B_{12}$ under different water content is made by Origin software. As shown in Figure 12, the smaller the value of $B_{12}$, the stronger the brittleness of coal mass. From the $B_{12}$ value of each pattern, the $B_{12}$ value of A-1 with water content of $5.4 \%$ is the smallest, and the brittleness of coal is stronger, followed by A-7 with water content of $5.4 \%$. From the average $B_{12}$ value of the pattern, the pattern with water content of $5.4 \%$ has the smallest value and the strongest brittleness, followed by the pattern with water content of $3.4 \%$.

After peak stress drop rate is of great significance to the rock brittleness characterization, but at the same time cannot be ignored before the peak stress-strain state for the influence of the rock brittleness. It is proposed that rock and rock damage when the release of elastic energy storage before total energy ratio and peak $B_{E}$ common characterization of rock brittleness indexes

$$
\begin{gathered}
B_{14}=B_{\text {post }}+B_{E}, \\
B_{\text {post }}=\frac{\sigma_{p}-\sigma_{r}}{\varepsilon_{r}-\varepsilon_{p}}, \\
B_{E}=\frac{W_{1}}{W_{2}},
\end{gathered}
$$

where $W_{1}$ is defined as the elastic energy released by rock failure (the blue area in the figure). The higher the index $B_{14}$ is, the more brittle the rock is. Figure 13 shows a diagram of brittleness index $B_{14}$ of coal.

According to the test data and the formula of $B_{10}$, the image of $B_{14}$ under different water content is made by Origin software. According to Figure 14, the greater the value of $B_{14}$ is, the stronger the brittleness of coal mass will be. From the $B_{14}$ value of each pattern, A- 6 with water content of $2.4 \%$ has 


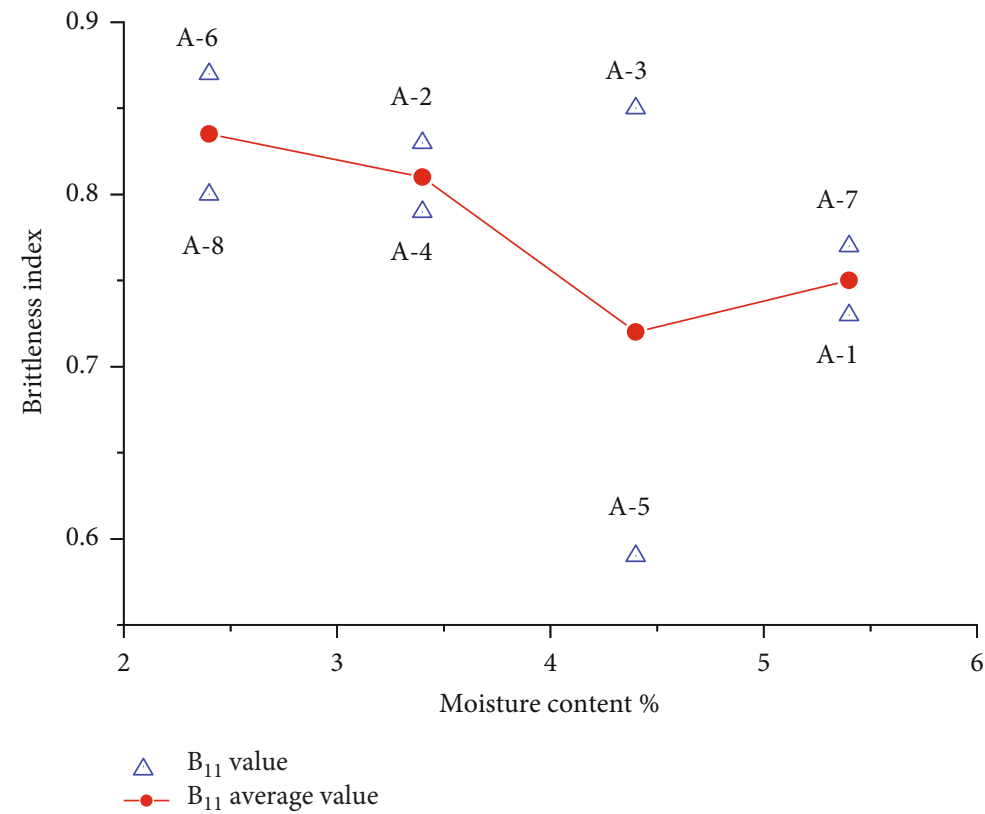

Figure 10: $B_{11}$ under different water content.
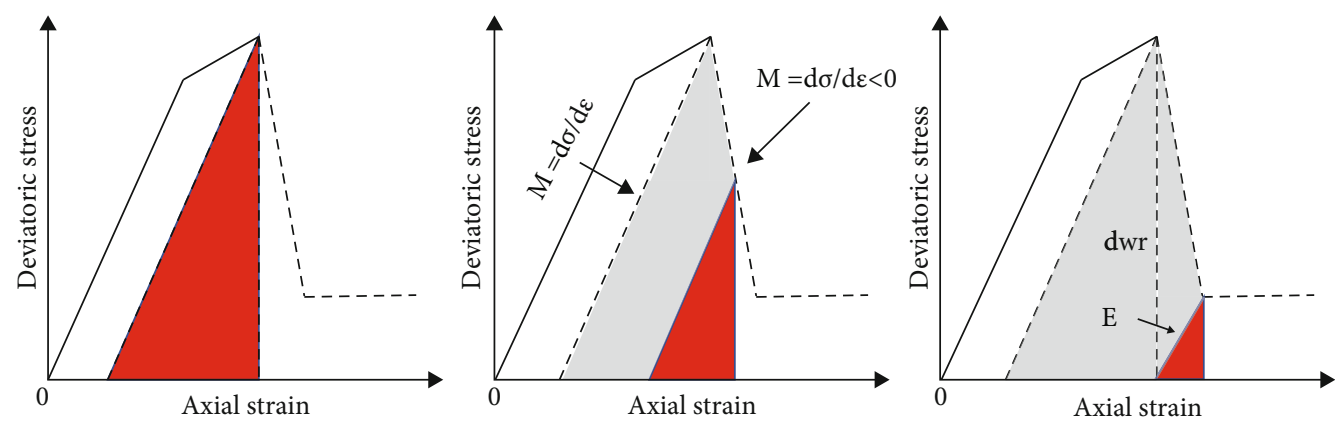

Figure 11: Schematic diagram of brittleness index $B_{12}$.

the largest $B_{14}$ value, and the brittleness is stronger, followed by A-4 with water content of $3.4 \%$. From the average $B_{14}$ value of the pattern, the pattern with water content of $3.4 \%$ has the largest $B_{14}$ value and the strongest brittleness, followed by the pattern with water content of $5.4 \%$.

Table 1 shows a summary of $B$ values at different water contents. The analysis shows that although the brittleness of samples with different water content is evaluated from different brittleness indexes, the results are consistent. The lower the water content, the greater the brittleness. With the increase of water content, the brittleness of coal samples decreases, showing certain softening characteristics.

\section{Constitutive Model}

The coal mass can be divided into six stages from loading to failure [56-58]: (1) crack closure stage, (2) elastic stage, (3) development stage of tensile crack, (4) the development stage of macrocrack, (5) rock structure stage, and (6) residual strength stage. However, the proportion of the crack closure stage to the axial strain stage cannot be ignored.
4.1. Duncan-Chang Model. Duncan-Chang model is described as follows [59, 60]:

$$
\begin{gathered}
\sigma=\frac{\varepsilon}{a+b \varepsilon}, \\
\sigma=\frac{\varepsilon}{a+b \varepsilon+c \varepsilon^{2}},
\end{gathered}
$$

where the coefficients of $a, b$, and $c$ are $a=1 / E_{0}, b=1 / \sigma_{C}$ $-2 / \varepsilon_{c} E_{0}, c=1 / E_{0} \varepsilon_{c}^{2}$.

$E_{0}$ is the initial modulus of elasticity $\left(E_{0}=d \sigma / d \varepsilon \mid \varepsilon\right.$ $\longrightarrow 0$ ), $\sigma_{c}$ is UCS strength (uniaxial compressive strength), and $\varepsilon_{c}$ is the corresponding axial strain.

The model is described as follows [61]:

$$
\sigma=E \varepsilon \exp \left[-\left(\frac{\varepsilon}{\varepsilon_{0}}\right)^{m}\right]
$$




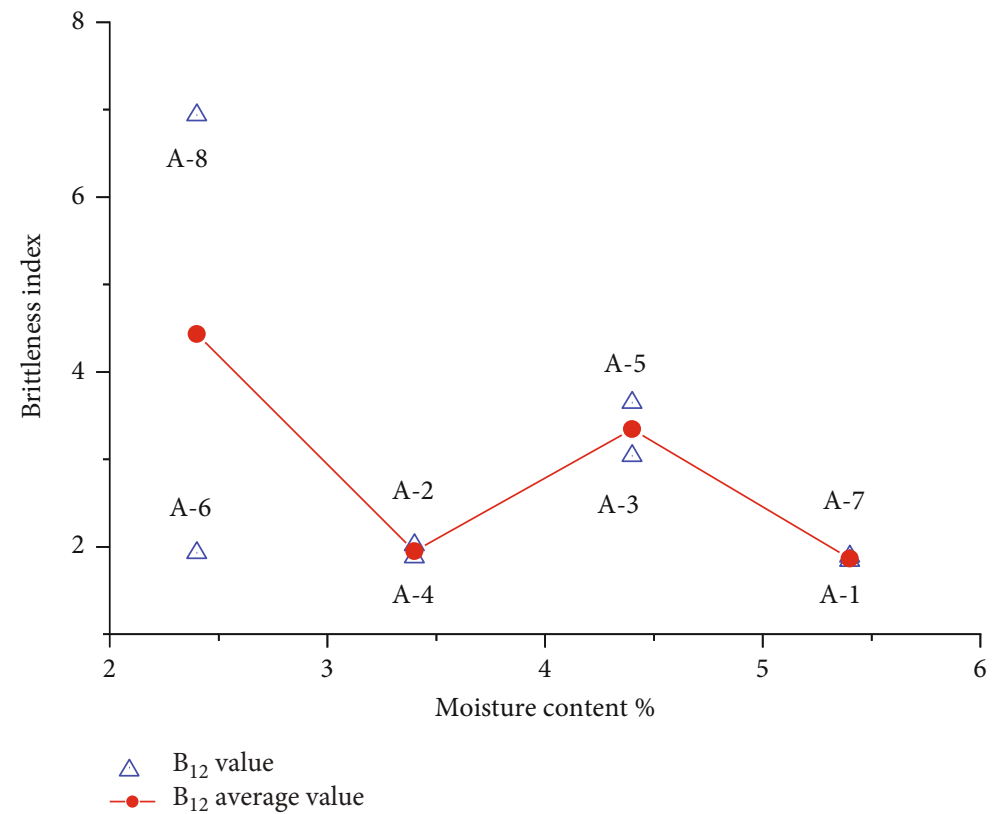

FIGURE 12: $B_{12}$ under different moisture content.

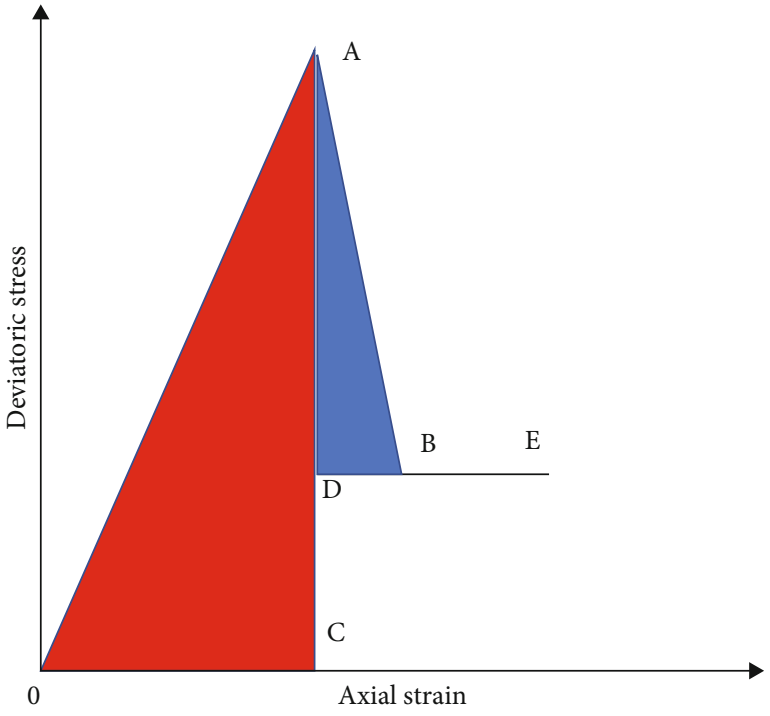

Figure 13: Schematic diagram of brittleness index $B_{14}$.

$E$ is the modulus of elasticity.

$$
\begin{aligned}
& m=\frac{1}{\ln \left(E \varepsilon_{c} / \sigma_{c}\right)}, \\
& \varepsilon_{0}=\frac{\varepsilon_{c}}{(1 / m)^{1 / m}} .
\end{aligned}
$$

The stress-strain curve from the experiment is converted to the stress-strain curve ignoring the fracture closure stage.
The model calculation based on Weber distribution is as follows $[62,63]$ :

$$
\sigma=E\left(\varepsilon-\varepsilon_{c}^{\prime}\right) \exp \left[-\left(\frac{\varepsilon-\varepsilon_{c}^{\prime}}{\varepsilon_{0}}\right)^{m}\right]
$$

The determination of the axial strain $\varepsilon_{x}$ used for differentiation is based on experiment.

$$
\sigma= \begin{cases}\frac{\varepsilon}{a+b \varepsilon+c \varepsilon^{2}} & \varepsilon \leq \varepsilon_{x}, \\ E\left(\varepsilon-\varepsilon_{c}^{\prime}\right) \exp \left[-\left(\frac{\varepsilon-\varepsilon_{c}^{\prime}}{\varepsilon_{0}}\right)^{m}\right] & \varepsilon>\varepsilon_{x},\end{cases}
$$

where $a=1 / E_{0}, b=1 / \sigma_{c}-2 / \varepsilon_{2} E_{0}, c=1 / E_{0} \varepsilon_{c}^{2}, m=1 / \ln E \varepsilon_{c} /$ $\sigma_{c}$, and $\varepsilon_{0}=\varepsilon_{c} /(1 / m)^{1 / m}$.

4.2. Practice of Duncan-Chang Model. The experimental data were put into the Duncan-Chang model, and the Origin software was used to draw the corresponding graphs. Table 2 shows the parameters of Duncan-Chang model.

As you can see from Figure 15, at the prepeak stage, the fitting curve is very close to the actual curve, which indicates the correctness of Duncan-Chang model and that the Duncan-Chang model has a correct direction for the study of coal mass.

From the strength of coal and rock, under the same water content and the same axial stress, the axial strain of sample A-6 is greater than that of sample A-8, indicating that under the same conditions, the structure and texture of sample A-6 are looser and softer than that of sample A8 , so the axial strain is larger. The axial strain of sample A4 is greater than that of sample A-2, indicating that under 


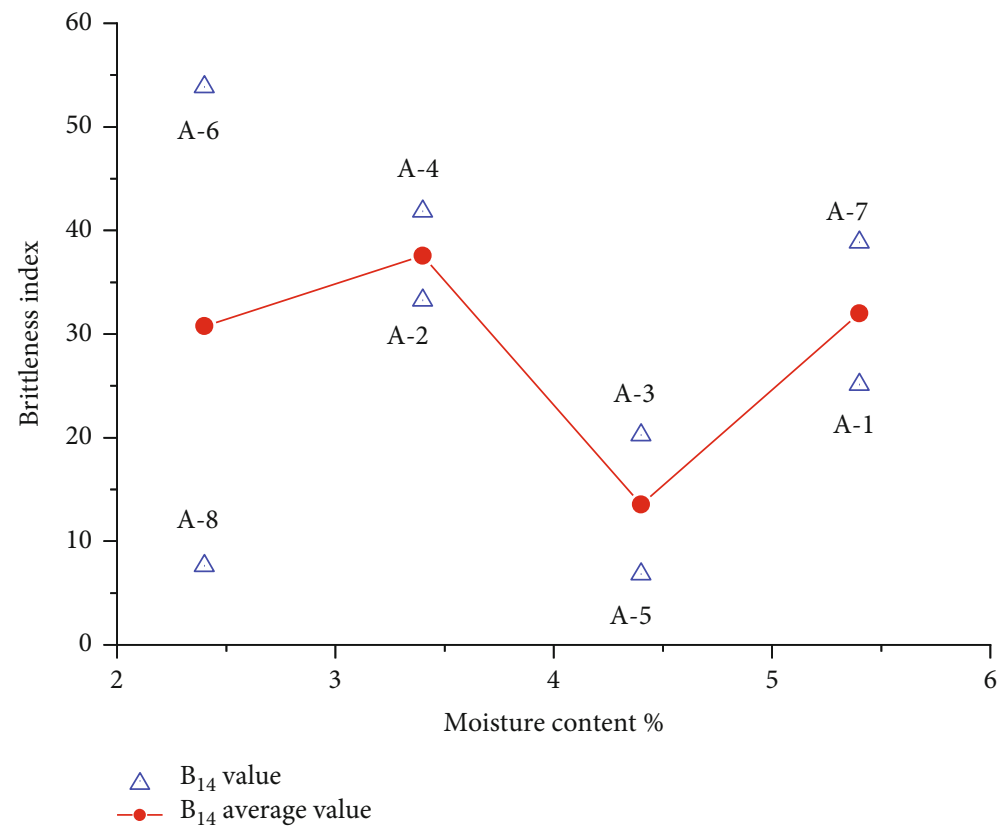

Figure 14: $B_{14}$ under different moisture content.

TABle 1: Summary of $B$ values at different water content.

\begin{tabular}{lcccccccc}
\hline Experimental group no. & Moisture content (\%) & $B_{7}$ & $B_{8}$ & $B_{9}$ & $B_{10}$ & $B_{11}$ & $B_{12}$ & $B_{14}$ \\
\hline A-8 & 2.4 & 0.39 & 0.7 & 2.28 & 0.06 & 0.8 & 6.94 & 7.62 \\
A-6 & 2.4 & 0.52 & 0.22 & 1.98 & 0.07 & 0.87 & 1.93 & 53.88 \\
A-2 & 3.4 & 0.45 & 0.25 & 1.97 & 0.07 & 0.83 & 2.02 & 33.28 \\
A-4 & 3.4 & 0.43 & 0.21 & 1.97 & 0.08 & 0.79 & 1.88 & 41.86 \\
A-3 & 4.4 & 0.32 & 0.35 & 1.96 & 0.04 & 0.85 & 3.04 & 20.25 \\
A-5 & 4.4 & 0.7 & 0.59 & 2.18 & 0.05 & 0.59 & 3.65 & 6.83 \\
A-7 & 5.4 & 0.39 & 0.16 & 1.96 & 0.06 & 0.77 & 1.89 & 38.86 \\
A-1 & 5.4 & 0.67 & 0.26 & 1.98 & 0.09 & 0.73 & 1.84 & 25.14 \\
\hline
\end{tabular}

TABle 2: Parameters of Duncan-Chang model.

\begin{tabular}{cccccccc}
\hline & $a$ & $b$ & $c$ & $E$ & $\varepsilon_{0}$ & $\varepsilon_{c}^{\prime}$ & $m$ \\
\hline A-1 & 0.13866 & -0.19682 & -0.30191 & 18.51 & 0.4968 & 0.069 & 6.286 \\
A-2 & 0.08417 & -0.20721 & 0.26803 & 39.53 & 0.3787 & 0.141 & 11.51 \\
A-3 & 0.02849 & -0.11827 & 1.39539 & 39.91 & 0.362 & 0.018 & 11.6 \\
A-4 & 0.10949 & -0.19167 & 0.09463 & 43.58 & 0.4959 & 0.211 & 10.06 \\
A-5 & 0.10036 & -0.19886 & 0.30131 & 20.4 & 0.6961 & 0.103 & 5.237 \\
A-6 & 0.15007 & -0.57475 & 0.74232 & 40.45 & 0.535 & 0.135 & 23.34 \\
A-7 & 0.18879 & -1.04542 & 2.26044 & 24.51 & 8.882 & 0.101 & 6.081 \\
A-8 & 0.03317 & -0.00628 & -0.09582 & 60.65 & 1.103 & 0.089 & 4.97 \\
\hline & & & & & & &
\end{tabular}

the same conditions, the structure and texture of sample A-4 are looser and softer than that of sample A-2, so the axial strain is larger. The intersection point in the figure is because A-2 of the sample has passed the peak stress point and started to decline. Because the Duncan-Chang model studies the stage before the peak stress, the part of A-2 decline can be ignored. The axial strain of sample A-5 is greater than that of sample A-3, indicating that under the same conditions, and the structure and texture of sample A-5 are looser and softer than that of sample A-3, so the axial strain is larger. The axial strain of sample A-1 is greater than that of sample A-7, indicating that under the same conditions, the structure and texture of sample A-1 are looser and softer than that of sample A-7, so the axial strain is larger. However, the fitting situation of the second half of sample A-7 is not very good, because the test data of the second half do not conform to the Duncan-Chang model and changes irregularly.

4.3. Function Fitting. When the Duncan-Chang model was used to fit the test data, a function was occasionally obtained that fitted the test data well, as shown below $[64,65]$ :

$$
\sigma= \begin{cases}\frac{\varepsilon}{a+b \varepsilon+c \varepsilon^{2}} & \varepsilon \leq \varepsilon_{x}, \\ d-e f^{\varepsilon} & \varepsilon>\varepsilon_{x} .\end{cases}
$$



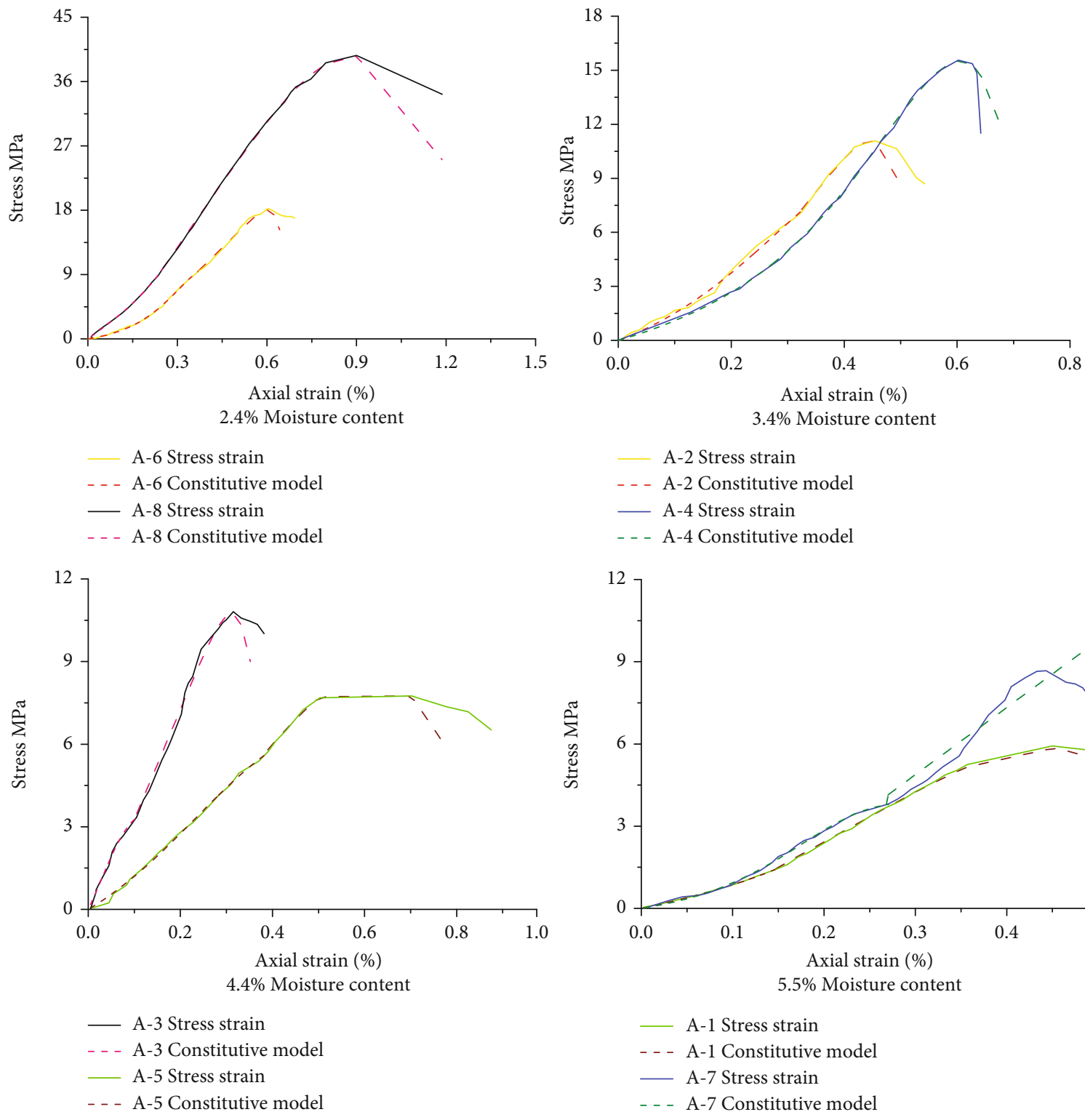
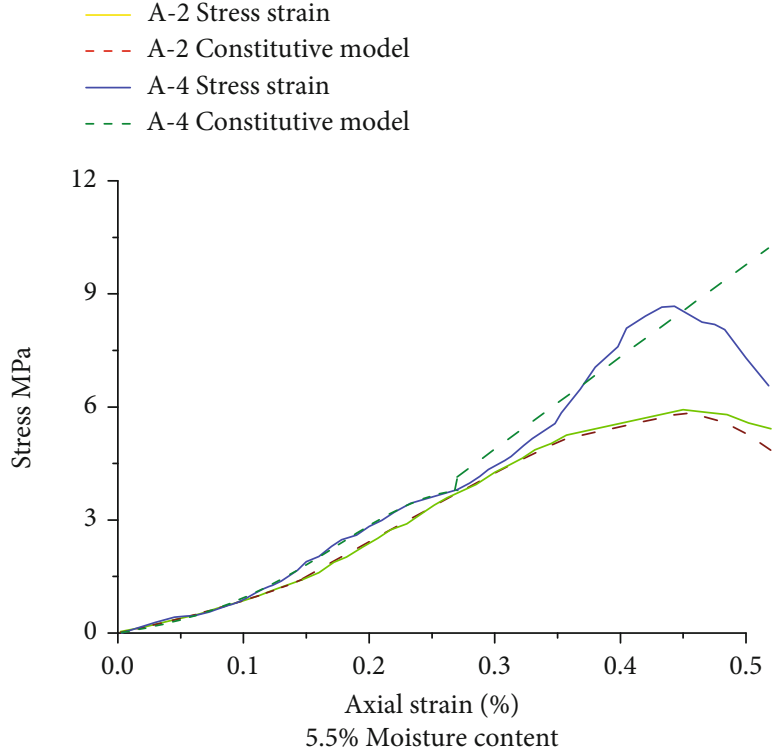

_ A-1 Stress strain
$\ldots$ - A-1 Constitutive model
_ A-7 Stress strain
_- A-7 Constitutive model

Figure 15: Constitutive model diagram of different water content.

The first half of this function is the same as the DuncanChang model $\left(\varepsilon \leq \varepsilon_{x}\right)$, and the second half refers to a new function.

The fitting Figure 16 is as follows:

The axial stress-strain diagrams at different water content fitted by this function are very close to the results fitted by the Duncan-Chang model, and the conclusions are the same. Water content has softened effect on coal and rock. Under the same conditions, sample A-8 is denser and harder than sample A-6. The structure of sample A-2 is denser, and the texture is harder than that of sample A-4. The structure of sample A-3 is denser, and the texture is harder than that of sample A-5.The structure of sample A-7 is denser, and the texture is harder than that of sample A-1. The failure mechanism of media cracks is further revealed through Figure 16. First, the primary cracks are compacted, and the cracks are reduced. Then, with the increase of load, new cracks appear and more cracks become.

In addition, it can be seen from Figure 16 that the peak stress of coal samples with different moisture content is also different. With the increase of moisture content, the peak stress of coal samples generally shows a downward trend. The peak stress of coal samples with moisture content of $2.4 \%$ is the largest, the peak stress of coal samples with moisture content of $5.4 \%$ is the smallest, and the peak stress decreases by about $75 \%$.

\section{Study on Seepage Characteristics}

According to the permeability measured by the test combined with other data from the test, the graph is drawn as follows: 


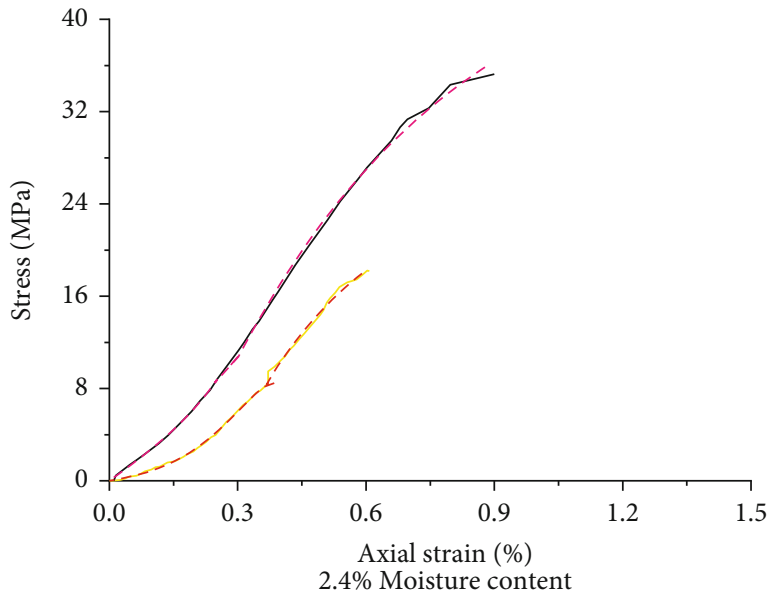

_- A-6 stress strain curve _- A-8 stress strain curve - - - A-6 fitting curve _- A- A fitting curve

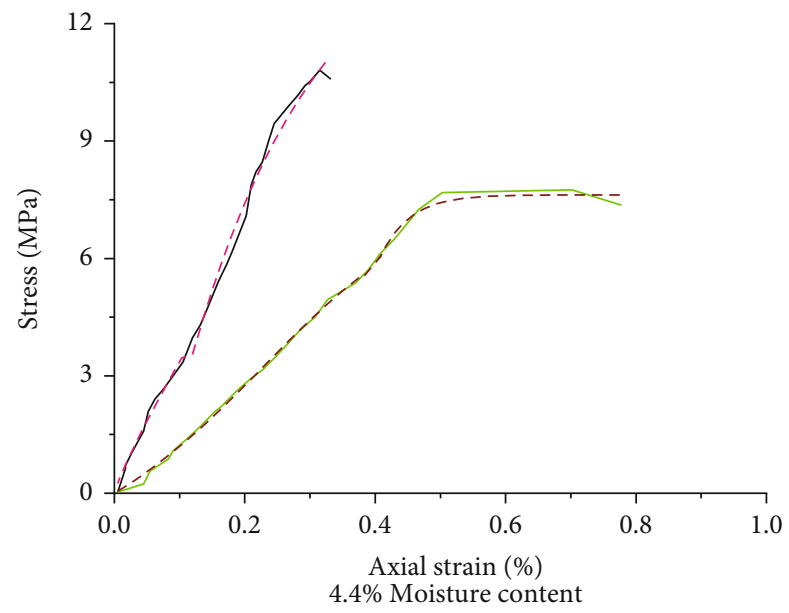

_ A-3 stress strain curve _- A-5 stress strain curve - - - A-3 fitting curve _- - A-5 fitting curve

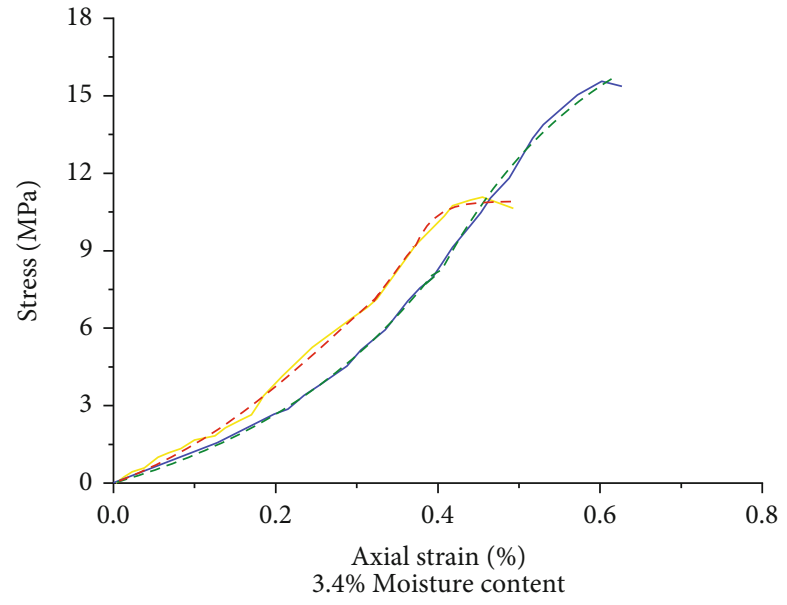

_- A-2 stress strain curve _- A-4 stress strain curve -. - A-2 fitting curve _- - A-4 fitting curve

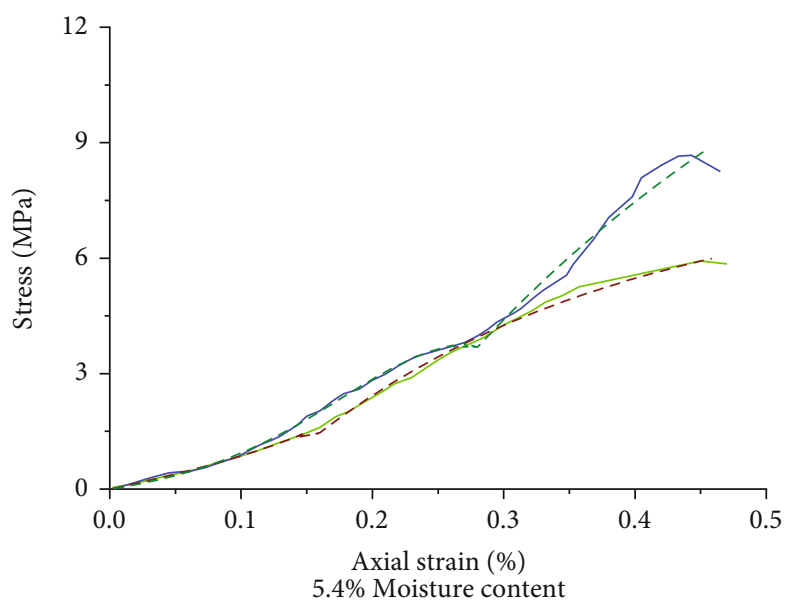

_ A-1 stress strain curve _- A-7 stress strain curve - - - A-1 fitting curve _. - A-7 fitting curve

FIGURE 16: Fitting diagram of different water content. 


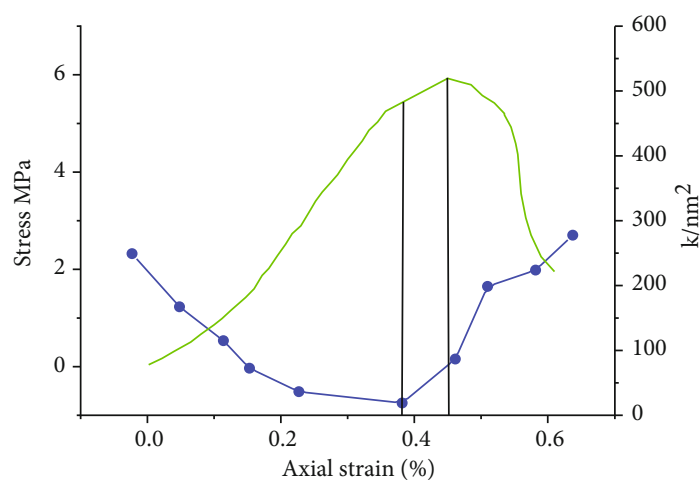

(a)

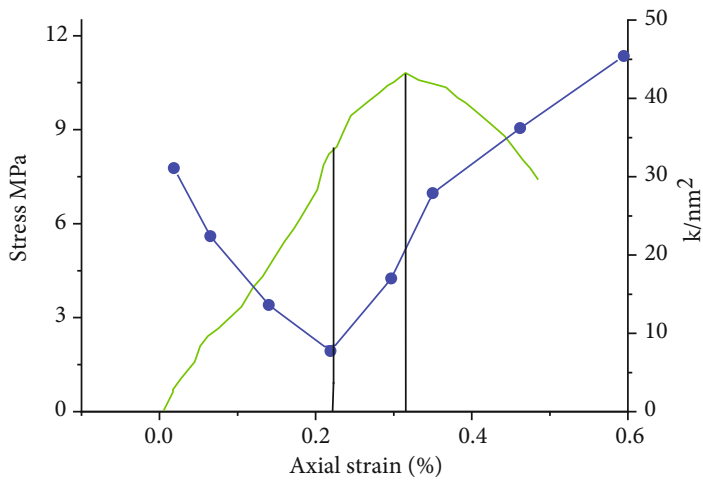

(c)

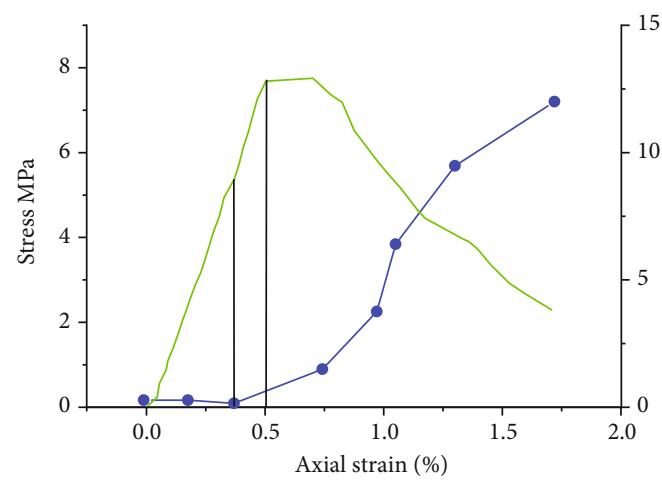

(e)

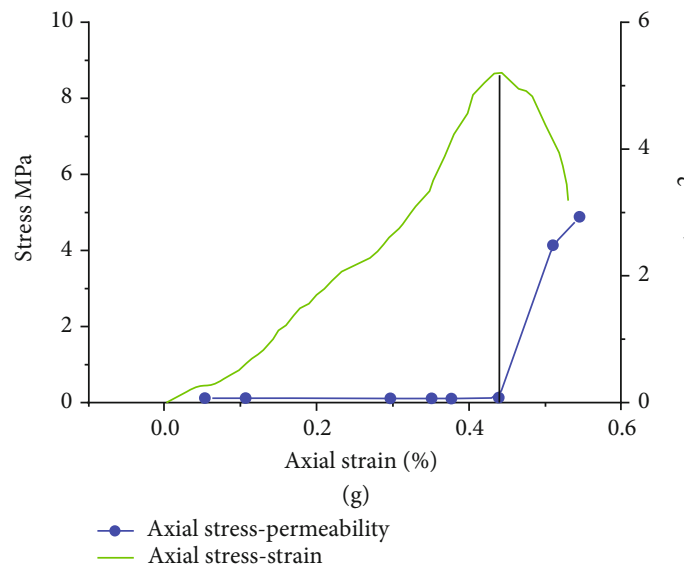

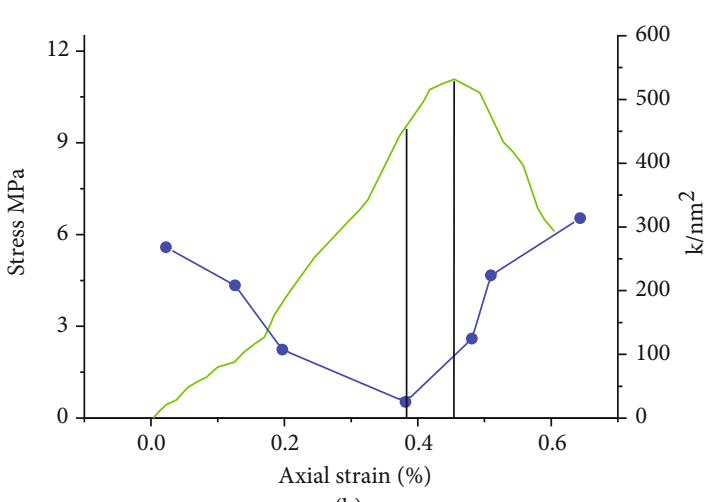

(b)

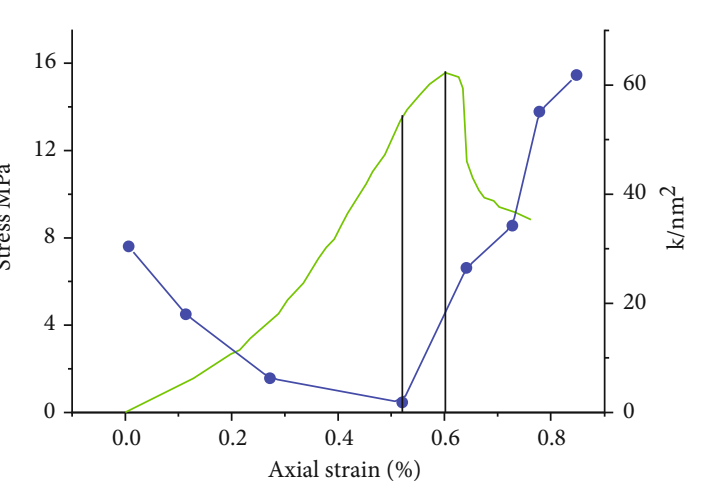

(d)

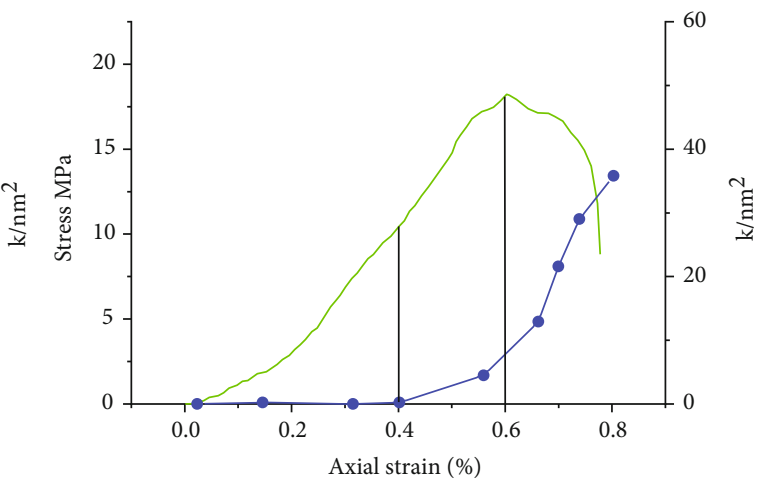

(f)

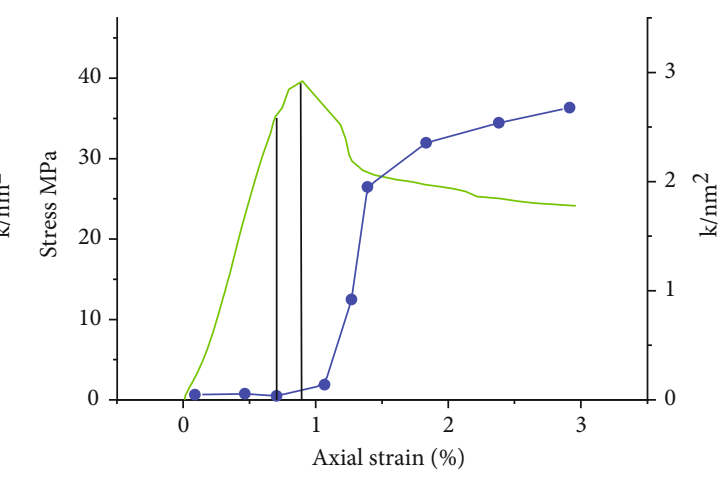

(h)

FIGURE 17: Stress-axial strain, permeability-axial strain diagram of the pattern. 
As you can see from Figure 17, the permeability changes of different coal types are basically the same, and the permeability of coal masses decreases first and then increases. At the initial loading and elastic deformation stage, the pattern cracks close gradually, and the permeability decreases with the increase of axial stress and strain. With the increase of the axial load, the axial stress and strain gradually increase, new cracks appear inside the pattern, new channels are added, and the permeability of the pattern gradually increases. After entering the failure stage, macrocracks appear and permeability increases rapidly.

\section{Conclusion}

In this paper, triaxial compression test combined with Origin graphic processing technology is used to carry out loading and unloading tests and image processing on coal mass patterns, identify and obtain useful information, and then analyze the mechanical behavior of coal mass and the study of seepage characteristics in unloading process. In data processing, many kinds of software have been used in numerical calculation and drawing, mainly including MATLAB, ABAQUS, EXCEL, and other software. In the analysis and research of this paper, the following conclusions are obtained:

According to the analysis of axial stress-strain graph, the coal mass can be divided into six stages from the initial loading to the failure stage: crack closure stage, elastic stage, development stage of tensile crack, the development stage of macrocrack, rock structure stage, and residual strength stage. It is also very important to know the crack closure stage of coal mass through the constitutive model, and the proportion of the crack in the axial strain cannot be ignored.

Through the analysis of permeability axial strain curve, it can be concluded that the permeability of coal and rock mass first decreases and then increases with the increase of load. Because at the beginning of loading, the crack of coal and rock mass begins to close, the channel in coal and rock body decreases, and the permeability decreases. As the load continues to increase, the coal and rock mass begin to produce new cracks, the channels increase, and the permeability increases. After loading to the failure stage, the coal and rock masses are completely destroyed, a large number of macrocracks are generated, and the permeability increases rapidly. The moisture content also reduces the strength of coal and rock, and the mechanical properties become worse. Through the in-depth study on the strength, mechanical properties, and permeability characteristics of damaged coal samples, the law is obtained, which plays a guiding role in coal mining and gas extraction, and can avoid coal mine disasters and accidents as much as possible.

\section{Data Availability}

The raw/processed data required to reproduce these findings are available upon request by contact with the corresponding author.

\section{Conflicts of Interest}

The authors declare that they have no conflicts of interest.

\section{References}

[1] L. Yuan, "Innovation and development of safety science and technology in coal industry of China," Safety in Coal Mines, vol. 46, no. S1, pp. 5-11, 2015.

[2] W. U. Cai, L. I. Ren, and F. U. Gui, "Training content design of preventing gas explosion accidents from the perspective of statistics of accident cases," Safety in Coal Mines, vol. 49, no. 8, pp. 266-268, 2018.

[3] G. Fu and Z. Zheng, "Research on reasons classification for unsafe acts in coalmine water accidents," Safety in coal mines, vol. 47, no. 7, p. 244, 2016.

[4] S. V. Valiulin, A. A. Onischuk, A. M. Baklanov et al., "Effect of coal mine organic aerosol on the methane/air lower explosive limit," International Journal of Coal Science \& Technology, vol. 7, no. 4, pp. 778-786, 2020.

[5] M. Więckowski, N. Howaniec, and A. Smoliński, "Effect of flow rates of gases flowing through a coal bed during coal heating and cooling on concentrations of gases emitted and fire hazard assessment," International Journal of Coal Science \& Technology, vol. 7, no. 1, pp. 107-121, 2020.

[6] G. U. Wei-juan, Z. H. Guo-shu, Z. H. Zhi-gen, C. H. Qing-hua, C. H. Ming-qiang, and X. U. Guang-quan, "Multi-index comprehensive identification and real-time warning of coal and gas outburst," Journal of Mining and Safety Engineering, vol. 30, no. 6, p. 922, 2013.

[7] J. Tan, C. L. Jiang, X. W. Li, and Y. J. Chen, "Relationship and research progress of coal and gas outburst mechanism and outburst prediction," Safety in Coal Mines, vol. 47, no. 4, pp. 186-190, 2016.

[8] C. Zhang, Z. T. Wang, D. Y. Yang, and C. C. Tian, "Study on mine safety manufacture accidents by factorial analysis," Coal Technology, vol. 35, no. 6, pp. 314-315, 2016.

[9] P. Gao and G. Fu, "Study on characteristics and occurrence regularities of roof accidents in Chinese coal mines," Industrial Safety and Environmental Protection, vol. 40, no. 8, pp. 46-48, 2014.

[10] K. Wang and F. Du, "Coal-gas compound dynamic disasters in China: a review," Process Safety and Environmental Protection, vol. 133, pp. 1-17, 2020.

[11] L. Zhu, F. Dang, Y. Xue, K. Jiao, and W. Ding, "Multivariate analysis of effects of microencapsulated phase change materials on mechanical behaviors in light-weight aggregate concrete," Journal of Building Engineering, vol. 42, article 102783, 2021.

[12] H. Cheng, N. Zhang, Y. Yang, Y. Dong, and W. Peng, "3-D dynamic evolution analysis of coal-rock damaged field and gas seepage field during the gas extraction process," Journal of Natural Gas Science and Engineering, vol. 56, pp. 444-454, 2018.

[13] Z. Zhao, N. Ma, H. Jia, and Y. Cheng, "Partitioning characteristics of gas channel of coal-rock mass in mining space and gas orientation method," International Journal of Mining Science and Technology, vol. 23, no. 6, pp. 873-877, 2013.

[14] J. 1. Hou, "Coal and gas outburst hazard analysis of complex coal seam based on fuzzy clustering method," Safety in Coal Mines, vol. 48, no. 6, p. 160, 2017. 
[15] F. Du, K. Wang, X. Zhang, C. Xin, L. Shu, and G. Wang, "Experimental study of coal-gas outburst: insights from coal-rock structure, gas pressure and adsorptivity," Natural Resources Research, vol. 29, no. 4, pp. 2481-2493, 2020.

[16] W. J. Yu, J. Zhang, Z. G. Yuan, and P. Wang, "Engineering mechanics behavior and surrounding rock control of mine loose coal and rock roadway," Coal Science and Technology, vol. 44, no. 6, pp. 52-59, 2016.

[17] Y. Weijian, F. Tao, W. Weijun et al., "Support problems and solutions of roadway surrounding rock for thin coal seams under complex conditions in southern China," Journal of China Coal Society, vol. 40, no. 10, pp. 2370-2379, 2015.

[18] P. F. Wu, W. G. Liang, M. T. Cao, J. F. Yang, and L. Li, "Experimental investigation on model I fracture characteristics of coal in different stratification," Chinese Journal of Underground Space and Engineering, vol. 13, no. S2, pp. 538-545, 2017.

[19] C. Zhang, S. G. Li, Q. Zeng, and H. F. Lin, "Numerical simulation on permeation laws of grouting in coal and rock fracture," Safety in coal mines, vol. 46, no. 12, p. 19, 2015.

[20] X. C. Li, L. Zhang, and Y. L. Zhao, "Evolution of gas-filled coal creep-seepage under conventional triaxial compression," Advanced Engineering Sciences, vol. 50, no. 4, pp. 55-62, 2018.

[21] Y. Huang, L. T. Zhou, and Z. F. Zhou, "Equations for permeability variation of fractured rock mass under high water pressure," Journal of Engineering Geology, vol. 26, no. 6, pp. 14331438, 2018.

[22] T. L. Xiao, X. P. Li, and Y. H. Guo, "Experimental study of failure characteristic of single jointed rock mass under triaxial compression tests," Rock and Soil Mechanics, vol. 33, no. 11, pp. 3251-3261, 2012.

[23] X. Wang, Z. Feng, H. Li, J. Wei, and L. Wang, "Reliability analysis of acoustic emission for coal and gas outburst under triaxial loading," Safety in Coal Mines, vol. 46, no. 8, pp. 160-163, 2015.

[24] Z. T. Bieniawski, "The effect of specimen size on compressive strength of coal," International Journal of Rock Mechanics and Mining Sciences \& Geomechanics Abstracts, vol. 5, no. 4, pp. 325-335, 1968.

[25] S. Wang, D. Elsworth, and J. Liu, "Permeability evolution during progressive deformation of intact coal and implications for instability in underground coal seams," International Journal of Rock Mechanics and Mining Sciences, vol. 58, pp. 34-45, 2013.

[26] G. Yin, Y. Liu, M. Li, B. Deng, and J. Lu, "Influence of true triaxial loading-unloading stress paths on mechanical property and permeability of coal," Journal of the China Coal Society, vol. 43, no. 1, pp. 131-136, 2018.

[27] Y. Xue, F. Gao, Y. N. Gao, and X. Liang, "Research on mininginduced permeability evolution model of damaged coal in post-peak stage," Journal of China University of Mining \& Technology, vol. 46, no. 3, pp. 521-527, 2017.

[28] Y. Xue, F. Gao, Y. Gao, X. Liang, Z. Zhang, and Y. Xing, "Thermo-hydro-mechanical coupled mathematical model for controlling the pre- mining coal seam gas extraction with slotted boreholes," International Journal of Mining Science and Technology, vol. 27, no. 3, pp. 473-479, 2017.

[29] Y. Xue, F. Gao, T. Teng, and Y. Xing, "Effect of gas pressure on rock burst proneness indexes and energy dissipation of coal samples," Geotechnical and Geological Engineering, vol. 34, no. 6, pp. 1737-1748, 2016.
[30] X. G. Liu, Study on the Deformation and Failure Characteristics and the Permeation Behavior of Gas-Saturated Coal, China University of Mining \& Technology, 2013.

[31] R. Yuan, C. Chen, X. Wei, and X. Li, "Heat-fluid-solid coupling model for gas-bearing coal seam and numerical modeling on gas drainage promotion by heat injection," International Journal of Coal Science \& Technology, vol. 6, no. 4, pp. 564-576, 2019.

[32] W. Zhao, K. Wang, R. Zhang, H. Dong, Z. Lou, and F. An, "Influence of combination forms of intact sub-layer and tectonically deformed sub-layer of coal on the gas drainage performance of boreholes: a numerical study," International Journal of Coal Science \& Technology, vol. 7, no. 3, pp. 571580, 2020.

[33] D. Guo, P. Lv, J. Zhao, and C. Zhang, "Research progress on permeability improvement mechanisms and technologies of coalbed deep-hole cumulative blasting," International Journal of Coal Science \& Technology, vol. 7, pp. 329-336, 2020.

[34] Y. Xue, J. Liu, F. Dang, X. Liang, S. Wang, and Z. Ma, "Influence of $\mathrm{CH}_{4}$ adsorption diffusion and $\mathrm{CH}_{4}$-water two-phase flow on sealing efficiency of caprock in underground energy storage," Sustainable Energy Technologies and Assessments, vol. 42, p. 100874, 2020.

[35] Y. Xue, P. G. Ranjith, F. Dang et al., "Analysis of deformation, permeability and energy evolution characteristics of coal mass around borehole after excavation," Natural Resources Research, vol. 29, no. 5, pp. 3159-3177, 2020.

[36] Y. Xue, T. Teng, F. Dang, Z. Ma, S. Wang, and H. Xue, "Productivity analysis of fractured wells in reservoir of hydrogen and carbon based on dual-porosity medium model," International Journal of Hydrogen Energy, vol. 45, no. 39, pp. 20240-20249, 2020.

[37] K. Anyim and Q. Gan, "Fault zone exploitation in geothermal reservoirs: production optimization, permeability evolution and induced seismicity," Advances in Geo-Energy Research., vol. 4, no. 1, pp. 1-12, 2020.

[38] H. Sidiq, R. Amin, and T. Kennaird, "The study of relative permeability and residual gas saturation at high pressures and high temperatures," Advances in Geo-Energy Research, vol. 1, no. 1, pp. 64-68, 2017.

[39] L. Chen, Research on Failure Strain and Permeability Evolution of the Coal Ahead of Working Face and Its Application, China University of Mining \& Technology, Beijing, 2016.

[40] Z. H. Xia, X. B. Zhang, C. Yao et al., "Experimental studies on seepage characteristics during the loading and unloading confining pressure of post-peak fractured rock," Journal of China Coal Society, vol. 44, no. 11, pp. 3379-3387, 2019.

[41] P. Hou, X. Liang, Y. Zhang, J. He, F. Gao, and J. Liu, "3D multiscale reconstruction of fractured shale and influence of fracture morphology on shale gas flow," Natural Resources Research, vol. 30, no. 3, pp. 2463-2481, 2021.

[42] Y. Xue, Z. Cao, and Z. Li, "Destabilization mechanism and energy evolution of coal pillar in rockburst disaster," Arabian Journal of Geosciences, vol. 13, no. 13, pp. 1-13, 2020.

[43] Y. Xue, J. Liu, P. G. Ranjith, X. Liang, and S. Wang, "Investigation of the influence of gas fracturing on fracturing characteristics of coal mass and gas extraction efficiency based on a multi-physical field model," Journal of Petroleum Science and Engineering, vol. 206, p. 109018, 2021.

[44] F. Ghasemi, M. Ghaedi, and M. Escrochi, "A new scaling equation for imbibition process in naturally fractured gas 
reservoirs," Advances in Geo-Energy Research, vol. 4, no. 1, pp. 99-106, 2020.

[45] Y. Xue, J. Liu, X. Liang, and Z. Y. Ma, "Nonlinear evolution characteristics of acoustic emission and fracture mechanism of coal under gas pressure," Chinese Journal of Geotechnical Engineering, vol. 43, pp. 241-245, 2021.

[46] Y. Rafiei and M. Motie, "Improved reservoir characterization by employing hydraulic flow unit classification in one of Iranian carbonate reservoirs," Advances in Geo-Energy Research, vol. 3, no. 3, pp. 277-286, 2019.

[47] J. Liu, Y. Xue, Q. Zhang, K. Yao, X. Liang, and S. Wang, "Micro-cracking behavior of shale matrix during thermal recovery: insights from phase-field modeling," Engineering Fracture Mechanics, vol. 239, p. 107301, 2020.

[48] J. Liu, X. Liang, Y. Xue, K. Yao, and Y. Fu, "Numerical evaluation on multiphase flow and heat transfer during thermal stimulation enhanced shale gas recovery," Applied Thermal Engineering, vol. 178, p. 115554, 2020.

[49] Y. Xue, P. G. Ranjith, F. Gao et al., "Mechanical behaviour and permeability evolution of gas-containing coal from unloading confining pressure tests," Journal of Natural Gas Science and Engineering, vol. 40, pp. 336-346, 2017.

[50] Z. Z. Cao, Y. L. Ren, Q. T. Wang, B. H. Yao, and X. C. Zhang, "Evolution mechanism of water-conducting channel of collapse column in karst mining area of southwest China," Geofluids, vol. 2021, Article ID 6630462, 2021.

[51] Y. Xue, F. Dang, F. Liu et al., "An elastoplastic model for gas flow characteristics around drainage borehole considering post-peak failure and elastic compaction," Environmental Earth Sciences, vol. 77, no. 19, pp. 1-18, 2018.

[52] E. Broni-Bediako and R. Amorin, "Experimental study on the effects of cement contamination in a water based mud," Advances in Geo-Energy Research, vol. 3, no. 3, pp. 314-319, 2019.

[53] Y. Xue, T. Teng, L. Zhu et al., "Evaluation of the non-Darcy effect of water inrush from karst collapse columns by means of a nonlinear flow model," Water, vol. 10, no. 9, p. 1234, 2018.

[54] J. Liu, Y. Xue, W. Chen, P. Hou, S. Wang, and X. Liang, "Variational phase-field model based on lower-dimensional interfacial element in FEM framework for investigating fracture behavior in layered rocks," Engineering Fracture Mechanics, vol. 255, p. 107962, 2021.

[55] Y. Xue, F. Dang, Z. Cao et al., "Deformation, permeability and acoustic emission characteristics of coal masses under mininginduced stress paths," Energies, vol. 11, no. 9, p. 2233, 2018.

[56] P. Hou, X. Liang, F. Gao, J. B. Dong, J. He, and Y. Xue, “Quantitative visualization and characteristics of gas flow in $3 \mathrm{D}$ porefracture system of tight rock based on Lattice Boltzmann simulation," Journal of Natural Gas Science and Engineering, vol. 89, article 103867, 2021.

[57] L. Zhu, F. Dang, Y. Xue, W. Ding, and L. Zhang, "Analysis of micro-structural damage evolution of concrete through coupled X-ray computed tomography and gray-level cooccurrence matrices method," Construction and Building Materials, vol. 224, pp. 534-550, 2019.

[58] Y. Xue, F. Gao, and X. Liu, "Effect of damage evolution of coal on permeability variation and analysis of gas outburst hazard with coal mining," Natural Hazards, vol. 79, no. 2, pp. 9991013, 2015.

[59] T. Teng, Y. Xue, and C. Zhang, "Modeling and simulation on heat-injection enhanced coal seam gas recovery with experi- mentally validated non-Darcy gas flow," Journal of Petroleum Science and Engineering, vol. 177, pp. 734-744, 2019.

[60] Z. Z. Cao, P. Xu, Z. H. Li, M. X. Zhang, Y. Zhao, and W. L. Shen, "Joint bearing mechanism of coal pillar and backfilling body in roadway backfilling mining technology," CMC-Computers Materials \& Continua, vol. 54, no. 2, pp. 137-159, 2018.

[61] X. Liang, P. Hou, Y. Xue, X. J. Yang, F. Gao, and J. Liu, “A fractal perspective on fracture initiation and propagation of reservoir rocks under water and nitrogen fracturing," Fractals, vol. 29, no. 7, p. 2150189, 2021.

[62] J. Liu, X. Liang, Y. Xue, Y. Fu, K. Yao, and F. Dou, "Investigation on crack initiation and propagation in hydraulic fracturing of bedded shale by hybrid phase-field modeling," Theoretical and Applied Fracture Mechanics, vol. 108, p. 102651, 2020.

[63] L. Zhu, F. Dang, Y. Xue, W. Ding, L. Zhang, and X. Xiong, "Meso-scale damage detection and assessment of concrete under dynamic compression loading using X-ray computed tomography," Materials Characterization, vol. 176, p. 111149, 2021.

[64] J. Liu, K. Yao, Y. Xue, X. Zhang, Z. Chong, and X. Liang, "Study on fracture behavior of bedded shale in three-pointbending test based on hybrid phase-field modelling," Theoretical and Applied Fracture Mechanics, vol. 104, p. 102382, 2019.

[65] L. Zhu, F. Dang, Y. Xue, W. Ding, and K. Jiao, "Experimental investigation of the thermal and mechanical properties of lightweight aggregate concrete mixed with microencapsulated phase change materials," International Journal of Energy Research, vol. 45, no. 9, pp. 12864-12878, 2021. 